\title{
CRIMINALIDAD ORGANIZADA Y CRIMINALIDAD ECONÓMICA: LOS RIESGOS DE UN MODELO DIFERENCIADO DE DERECHO PENAL
}

\author{
Juan Oberto Sotomayor Acosta*
}

\begin{abstract}
1. Introducción; 2. "Criminalidad organizada" y "riminalidad económica" como objetivos prioritarios de los sistemas penales de los paises desarrollados; 3. La convergencia: el modelo diferenciado y sus riesgos: a. El modelo diferenciado en el ámbito de la criminalidad organizada; $b$. El modelo diferenciado en el ámbito de la criminalidad económica; c. Los riesgos del modelo diferenciado; 4. La lucha contra la criminalidad organizada en Colombia: el contexto; 5. Consecuencias de la lucha contra la criminalidad organizada en el sistema penal colombiano: a. La legislación penal colombiana: de la excepción a la regla; b. Subordinación del derecho penal sustantivo al proceso: la creciente autonomía del proceso penal como mecanismo de control social; c. Transformación de los fines de la pena: la condena sin proceso; $d$. Instrumentalización politica; 6. A manera de conclusión: los desafios del derecho en Colombia.
\end{abstract}

\section{Introducción}

Al diferenciar las funciones del derecho en Europa y América Latina, el profesor Juan Bustos Ramírez decía, con razón, que "[e]l Derecho Penal latinoamericano ha sido pensado atemporal y aespacialmente. Pero no sólo ello surge en relación a la configuración de los códigos, esto es, al hecho de que el CP chileno no sea diferente al CP español de 1948, que el CP peruano sea semejante al suizo, que el $\mathrm{CP}$ argentino sea muy parecido al italiano de Zanardelli, o bien, y de modo general que el CP tipo para Latinoamérica resulte muy parecido al proyecto alemán del año 62. Sino, también en razón, y espacialmente por eso, a la forma de concreción del estudio jurídico-penal. Éste se ha limitado exclusivamente a una conceptualización ético-filosófica en relación a la norma jurídica y al sujeto responsable. En cuanto a la norma, concibiéndola, entonces como un puro espíritu legislativo producto de la cabeza del legislador o del jurista, y, por tanto, como un ente con existencia propia e independiente en el mundo de las ideas. De ahí, entonces, que su estudio permite homologar sin mayor problema y sin diferencias, un texto de Derecho Penal latinoamericano con otro cualquiera en Europa; ciertamente, a este nivel de abstracción y del puro plano de las ideas, no puede haber diferencia alguna. Las realidades aparecen iguales, da lo mismo que un país esté en el norte o en el sur, que sea subdesarrollado o desarrollado, que sea dependiente o independiente, que sea una dictadura o una democracia".'

\footnotetext{
* Profesor de la Universidad EAFIT, Medellín, Colombia.

${ }^{1}$ Bustos RamíreZ, J., "Criminología crítica y derecho penal latinoamericano", en Obras Completas, Tomo II: Control social y otros estudios, Lima, ARA Editores, 2004, pp. 502-503,
} 
Sotomayor - Criminalidad organizada y criminalidad económica...

Si bien el recurso a la importación acrítica de las normas y modelos europeos no ha desaparecido en nuestro continente, lo cierto del caso es que en los últimos años la mencionada unificación legislativa (o por lo menos algunas de sus manifestaciones más importantes) no podría ser siempre atribuida a la dependencia cultural y ni siquiera a la transnacionalización de las instituciones de control social que durante los primeros desarrollos de la criminología tuvo lugar por cuenta de los congresos, encuentros y demás actividades de las asociaciones de criminólogos y juristas. ${ }^{2}$ En la actualidad, un número cada vez más creciente de decisiones no sólo económicas sino también políticas (y por supuesto también las referidas al control del delito) se producen en los países centrales, desde donde se orientan o se imponen a los países periféricos, en consonancia con la concentración de poder político general y económico de los primeros. ${ }^{3}$ Situación que se refleja entre otros aspectos, en la instauración de una justicia penal internacional y en la creciente tendencia a la unificación legislativa, ${ }^{4}$ que no sólo se manifiesta en los países pertenecientes a un mismo bloque económico y político (como es el caso de los países pertenecientes a la Unión Europea), sino que se extiende a toda su área de influencia.

No obstante, como en su momento lo denunciara el profesor Bustos Ramírez, la aplicación de dichos modelos a realidades tan diversas de aquéllas donde han surgido, lleva a consecuencias no necesariamente coincidentes con las que se producen en los sitios de origen, pues dicha unificación legislativa tiene lugar a partir de realidades muy diferentes y unas relaciones de poder claramente desiguales entre los países. ${ }^{5}$

${ }^{2}$ Ver Del Olmo, R., América Latina y su criminología, México, Siglo XXI, 1984, pp. 81 y ss.

3 Cfr. SANTOS, B. DE S., La globalización del Derecho. Los nuevos caminos de la regulación y la emancipación, Bogotá, Universidad Nacional-ILSA, 1998, pp. 37-67 y 80-85; CAPELLA HERnÁNDEZ, J. R., "Estado y derecho ante la mundialización: aspectos y problemáticas generales", en CAPELLA HERNÁNDEZ, J. R. (Coordinador), Transformaciones del derecho en la mundialización, Madrid, Consejo General del Poder Judicial, 1999, pp. 85-121, en particular, 119-121; TERRADILLOS, J., "El derecho penal de la globalización: luces y sombras", en CAPELla HERnÁNDEZ, J. R. (Coordinador), Transformaciones del derecho..., p. 204.

${ }^{4}$ En general, cfr. MERCADO, P., "El proceso de globalización, el Estado y el Derecho", en Portilla CONTReras, G., Mutaciones del Leviatán. Legitimación de los nuevos modelos penales, Madrid, Universidad Internacional de Andalucía - Akal, 2005, pp. 133-138. Sobre los aspectos estrictamente penales, Terradillos, J., "El derecho penal de la globalización..., pp. 185-217; Donini, M., "Escenarios del Derecho penal en Europa a principios del siglo XXI", en MIR PUIG, S. y CORCOY BidASOlo, M. (Directores) - GÓMEZ MARTín, V. (Coordinador), La política criminal en Europa, Atelier, Barcelona, 2004, pp. 43 y 44; SiLVA SÁNCHEZ, J. M., La expansión del derecho penal. Aspectos de la politica criminal en las sociedades postindustriales, $2^{\text {a }}$ edición, Madrid, Civitas, 2001, pp. 81 y ss.; y ARIAs Holguín, D. P., A propósito de la discusión sobre el derecho penal "moderno" y la sociedad del riesgo, Cuaderno de Investigación, No. 42, Medellín, Universidad EAFIT, 2006, pp. 22-28.

5 Bustos Ramírez, J., "Estructura jurídica y Estado en América Latina", en Rusche, G. y Kirchheimer, O., Pena y estructura social, Bogotá, Temis, 1984, pp. L a LV; en igual sentido, Terradillos, J., "El derecho penal en la globalización...”, págs. 185 a 216, en especial, pp. 203210; y Arias Holguín, D. P., A propósito de la discusión..., p. 27. Sobre ello han llamado la atención algunos estudios latinoamericanos: GARZÓN VALDÉS, E., "Acerca de las funciones del derecho en 
Esta situación se refleja bastante bien en dos de los temas que en mayor grado están determinando la configuración actual del derecho penal en los países desarrollados, cuales son el de la criminalidad organizada y la criminalidad económica.

\section{2. “Criminalidad organizada" y "criminalidad económica" como objetivos prioritarios de los sistemas penales de los países desarrollados}

A primera vista podría pensarse que las nociones de criminalidad organizada y criminalidad económica aluden a realidades muy diversas, las cuales inclusive ameritarían valoraciones diferentes desde el punto de vista del derecho penal, en tanto la primera suele en ocasiones vincularse directa o indirectamente a modelos orientados a la seguridad ciudadana, mientras la segunda se legitimaría en virtud de las necesidades de protección frente a los nuevos riesgos derivados del desarrollo social y tecnológico de las sociedades modernas. ${ }^{6}$

No obstante, desde otro punto de vista la conexión entre ambos fenómenos se torna visible cuando se afirma que el predominio de la economía de libre mercado y el desarrollo tecnológico, en especial en el ámbito de las telecomunicaciones, ha propiciado el movimiento de capitales, bienes y servicios, incrementando de manera notable el comercio internacional y al mismo tiempo los mecanismos de todo orden que lo posibilita, pues tales mecanismos, por supuesto, no sólo se encuentran a disposición de los agentes económicos legales. En otras palabras, según destacan algunos analistas, "desregulación de los mercados financieros, libertad de movimiento de capitales, redes internacionales de comercio, proceso de concentración de capitales, alzamiento de fronteras dentro de los espacios comunes, son todos elementos consustanciales de la economía mundial moderna que pueden ser caldo de cultivo del tráfico ilícito en general y de la criminalidad organizada en particular".

América Latina". Cuadernos de la Facultad de Derecho, Universidad de Palma de Mallorca, 3 1982, p. 204; en igual sentido, GARCíA MÉNDEZ, E., Autoritarismo y control social (Argentina-Uruguay-Chile), Buenos Aires, Hammurabi, 1987, pp. 231 a 243; Sotomayor ACOSTA, J. O., "Garantismo y derecho penal en Colombia", en JD, 1999 (35), pp. 92 y 93. Recientemente se ha ocupado de analizar este fenómeno con profundidad, LÓPEZ MEDINA, D. E., Teoría impura del derecho. La transformación de la cultura jurídica latinoamericana, Legis-Universidad de Los Andes, Universidad Nacional, Bogotá, 2004., pp. 1 a 69.

${ }^{6}$ En esta dirección, Paredes Castañón, J. M., "Sobre el concepto de Derecho penal del riesgo: algunas notas", en DPCRI, 2003 (4), p. 114; y DíEZ RIPOLLÉs, J. L., "De la sociedad del riesgo a la seguridad ciudadana", Revista electrónica de ciencia penal y criminología, 7, 2005. pp. 253-256.

7 Al respecto, ZÚÑIGA RodRíGUEZ, L., "Criminalidad organizada, Unión Europea y sanciones a empresas", consultado http://www.unifr.ch/ddp1/derechopenal/articulos/html/artzuniga.html, p. 4. 
Sotomayor - Criminalidad organizada y criminalidad económica...

Lo anterior hace de la distinción de las nociones de "criminalidad organizada" y "criminalidad económica" una tarea en ocasiones bastante compleja, de lo que el delito de "lavado de activos" constituye el mejor ejemplo. De ahí que se destaque cada día con mayor insistencia la relación existente entre ambas, aun cuando dicha relación pueda admitir diversas lecturas o perspectivas, de las cuales Foffani ${ }^{9}$ destaca principalmente tres:

a) La primera, parte de la existencia de una ósmosis sustancial entre los dos fenómenos, en tanto la criminalidad organizada es por naturaleza económica y la criminalidad económica es cada vez más organizada.

b) Dicha relación también podría mirarse de una manera más restringida, con miras a la identificación de las posibles interferencias de la criminalidad organizada con el mundo de la economía que pudieran tener relevancia penal.

c) Por último, la aludida relación también podría orientarse a la verificación de la existencia de formas de criminalidad económica que asumen las características estructurales de la denominada criminalidad organizada. En palabras del mencionado profesor italiano, se trata "de considerar si la economía, además de ser campo privilegiado de 'invasión' o de 'expansión' de una criminalidad organizada originada en otros sectores de la actividad humana, no es quizás ella misma una posible 'fuente' o 'caldo de cultivo' de nuevas y específicas formas de criminalidad organizada". ${ }^{10}$

Independientemente del punto de vista que se elija, lo cierto del caso es que cada día con mayor insistencia, la "lucha" contra las mencionadas manifestaciones criminales se ha convertido en objetivo prioritario de los sistemas penales de los países desarrollados, ${ }^{11}$ que por medio de muy diversos mecanismos la han ido extendiendo a los países de su área de influencia. Luego, con demasiada frecuencia se escuchan voces desde lugares muy diversos, y especialmente del mundo de la política y los medios masivos de comunicación social, que alertan sobre los peligros de estas formas de criminalidad y la necesidad de una respuesta penal "adecuada" a la gravedad del fenómeno.

En particular, la noción de "crimen organizado" ha llegado al discurso criminológico y jurídico penal convertida en una especie de fantasma, esto es, algo contra lo cual se precisa luchar aunque no se tenga del todo claro lo que es. Parece que el hecho de tratarse de un término surgido principalmente de la retórica de los

\footnotetext{
8 Cfr. Arias Holguín, D., "Lavado de activos y 'modernización' del derecho penal: el caso colombiano”, en NFP, 2007 (70), pp. 168-218.

${ }^{9}$ FOFFANI, L., "Criminalidad organizada y criminalidad económica", en RP, 2001 (7), p. 56.

${ }^{10}$ Foffani, L., "Criminalidad organizada...”, p. 57.

11 Al respecto, MEDINA ARIZA, J. J., "Una introducción al estudio criminológico del crimen organizado", en Ferré Olivé, J. C. y ANARTe Borrallo, E. (Eds.), Delincuencia organizada. Aspectos penales, procesales y criminológicos, Huelva, Universidad de Huelva, 1999, pp. 109-134; SÁNCHEZ GARCÍA DE PAZ, I., La criminalidad organizada. Aspectos penales, procesales, administrativos y policiales, Madrid, Dykinson, 2005, pp. 42 y ss.; y GARRIDO, V., STANGELAND, P. y REDONDO, S., Principios de criminologia, Valencia, Tirant lo blanch, 2006, pp. 751-776.
} 
REJ - Revista de Estudios de la Justicia - No 12 - Año 2010

políticos y del sensacionalismo de los medios de comunicación ha tornado su trasvase a categoría jurídica en una tarea compleja y no siempre lograda, dada su vaguedad y falta de rigor científico. ${ }^{12}$

En efecto, de "criminalidad organizada" se habla para referirse a un sinnúmero de delitos de muy diversas características y en algunos casos con muy poca relación entre sí, tales como el tráfico de drogas, tráfico y explotación laboral y sexual de seres humanos, tráfico ilegal de armas, falsificaciones, robo y tráfico ilegal de vehículos, delincuencia económica (blanqueo de dinero, estafa, fraude fiscal y de subvenciones, contrabando), corrupción, criminalidad informática, daños medioambientales, robo y tráfico de obras de arte, etc., e inclusive se ha pretendido también incluir fenómenos como el terrorismo y hasta el secuestro de personas. $^{13}$

\footnotetext{
${ }^{12}$ Como explica Weigend, V. D., "Los sistemas penales frente al reto del crimen organizado", en RIDP, 1997 (68), p. 548, “A pesar de sus numerosas definiciones que se ofrecen, la criminalidad organizada no deja de ser sino una imagen, una expresión aplicada a diversas realidades que se producen en diferentes momentos y lugares". En ello coincide de forma casi unánime la doctrina: entre otros, BLAKESLEY, L., "El sistema penal frente al reto del crimen organizado", en RIDP, 1997 (69), p. 107: "A pesar de los intentos por definirlo, el crimen organizado es un fenómeno escurridizo, complejo y con múltiples facetas. Es una idea popular, aunque no jurídica, que la definición puede ser utilizada de una manera tan genérica que la haga inútil”. Según ZAFFARONI, E. R., El crimen organizado. Una categoría frustrada, Bogotá, Leyer, 1996, p. 40: “... se trata de una categoría frustrada, o sea de una tentativa de categorización que acaba en una noción difusa". En igual dirección, ANARTE BORRALLO, E., "Conjeturas sobre la criminalidad organizada", en FERRÉ Olivé, J. C. y ANArte Borrallo, E. (Eds.), Delincuencia organizada..., pp. 20-25; De la CuESTA ARZAMENDI, J. L., "El derecho penal ante la criminalidad organizada: nuevos retos y límites", en GutiÉRREZ-Alviz CONRADO, F. y VALCARCE LÓPEZ, M. (Directores), La cooperación internacional frente a la criminalidad organizada, Sevilla, Universidad de Sevilla, 2001, pp. 87-94; FIANDACA, G., "Criminalità organizzata e controllo penale", en BAssiouni, M. C., LATAGLIATA, A., R. y STILE, A. M., (a cura di), Studi in onore di Giuliano Vassalli. Evoluzione e riforma del diritto e della procedura penale (1945-1990), Volumen II, Milano, Giuffrè, 1991, pp. 33-35; PAVARINI, M., "Lo sguardo artificiale sul crimine organizzato", en GIOSTRA, G. e INSOLERA, G. (a cura di), Lotta alla criminalità organizzata: gli strumenti normativi, Milano, Giuffrè, 1995, p. 79; INSOLERA, G., "Nociones de criminalidad organizada: concurso de personas y delitos asociativos", en VIRGOLINI - SLOKAR (Coordinadores), Nada personal... Ensayos sobre crimen organizado y sistema de justicia, Buenos Aires, Depalma, 2001, pp. 95-105; ORSI, O. G., Sistema penal y crimen organizado. Estrategias de aprehensión y criminalización del conflicto, Buenos Aires, Del Puerto, 2007, pp. 3 y ss.

13 Véase SÁNCHEZ GARCÍA DE PAZ, I., La criminalidad organiz̨ada..., pp. 46 y ss; y GARRIDO, V., Stangeland, P. y ReDondo, S., Principios de criminología, pp. 751-776. Muy crítico, ZAFFAroni, E. R., "En torno al concepto de 'crimen organizado", en VIRGOLINI - SLOKAR (Coordinadores), Nada personal..., p. 10, quien señala, con razón, que "no hay un concepto que abarque todo eso... Fenómenos tan heterogéneos deben ser combatidos con medidas particularizadas, adecuadas a las características de cada uno; de lo contrario, todos los intentos nacen destinados al fracaso... Nada se gana con pretender tratar del mismo modo el secuestro y la sobrefacturación".
} 
Sotomayor - Criminalidad organizada y criminalidad económica...

Pese a las dificultades, la noción se ha visto revalorizada a consecuencia de la importancia adquirida por la llamada criminalidad transnacional ${ }^{14}$ que se ha desarrollado a la par de los procesos de globalización económica y progreso tecnológico de los últimos años, que ha propiciado la aparición de nuevas modalidades de realización de los delitos tradicionales, como también, al parecer, de nuevos intereses que proteger frente a nuevas modalidades de ataque. ${ }^{15}$ Revalorización a la que también ha contribuido, en buen grado, la proliferación de tratados y convenios internacionales, entre los que cabe destacar la Convención de las Naciones Unidas contra la delincuencia organizada transnacional, del 15 de noviembre de 2000, así como algunas medidas adoptadas en el seno de la Unión Europea. ${ }^{16}$ Se trata de una normatividad que sin duda ha legitimado el uso de la expresión, pese a que al momento de la delimitación del fenómeno se recurre a nociones que siguen adoleciendo de las mismas falencias de indeterminación y heterogeneidad que desde antes se denunciaba.

Con razón se ha dicho que la expresión "criminalidad organizada" no es descriptiva sino valorativa, pues se trata ante todo de una idea "elaborada con criterios de naturaleza comunicativa y simbólica que sirven para brindar los fundamentos de una política de 'lucha' con caracteres de excepcionalidad o emergencia". ${ }^{17}$ Excepcionalidad a la que se acude ahora en razón de una presunción de peligrosidad de ciertos comportamientos ${ }^{18}$ y de las dificultades, especialmente probatorias, que conlleva la prevención y represión de los mismos, sobre todo en relación con la criminalidad transnacional, por la disociación que se produce entre el resultado y la acción de los más importantes agentes dentro de la organización criminal. ${ }^{19}$

\section{La convergencia: el modelo diferenciado y sus riesgos}

Esta lucha contra el crimen organizado, incluido el de contenido estrictamente económico, está derivando en un modelo diferenciado de derecho penal: por un

\footnotetext{
14 Albrecht, H. J., Criminalidad transnacional, comercio de narcóticos y lavado de dinero, Bogotá, Universidad Externado de Colombia, 2001, pp. 11 y ss.; y CERVINI, R., "Los filtros sistémicos del crimen organizado en materia económica y financiera", en YACOBUCCI, G. (Coordinador), El crimen organizado. Desafios y perspectivas en el marco de la globalización, Buenos Aires, Abaco de Rodolfo Depalma, 2005, p. 403.

${ }^{15}$ Cfr. Silva SÁnCHEZ, J. M., La expansión del derecho penal..., p. 86.

${ }^{16}$ Cfr. SÁNCHEZ GARCÍA DE PAZ, I., La criminalidad organizada ..., pp. 83-98.

17 YACOBUCCI, G., "Política criminal y delincuencia organizada", en YACOBUCCI, G. (Coordinador), El crimen organizado..., p. 69. En igual sentido, ZAFFARONI, E. R., "En torno al concepto de "crimen organizado", pp. 9-15; PAVARINI, M., "Lo sguardo artificiale...", p. 77; INSOLERA, G., "Nociones de criminalidad organizada...”, p. 102; ORSI, O. G., Sistema penal y crimen organizado..., p. 198.

18 Tal como pone de presente PAVARINI, M., "Lucha contra la criminalidad organizada y 'negociación' de la pena”, en VIRGOLINI - SLOKAR (Coordinadores), Nada personal..., p. 22.

${ }^{19}$ En tal sentido, SILVA SÁNCHEZ, J. M., La expansión del derecho penal..., p. 87.
} 
lado, el sistema clásico de derecho penal y por otro, los excepcionales de lucha contra la criminalidad organizada o la criminalidad económica, caracterizados fundamentalmente por la restricción de algunos principios y garantías, así como por la flexibilización de algunas de las reglas de imputación de la responsabilidad penal, todo en aras de facilitar la prevención y represión de los delitos. ${ }^{20}$

\section{a. El modelo diferenciado en el ámbito de la criminalidad organizada}

En el ámbito de la criminalidad organizada, especialmente de corte transnacional, el modelo de "lucha" está conduciendo a la ampliación o agravación de tipos tradicionales como el de asociación para delinquir, la punición de actos preparatorios, la no diferenciación entre actos de tentativa y de consumación, entre autoría y participación, así como a plantear la responsabilidad penal de las personas jurídicas, los beneficios por colaboración con la justicia y la extensión de la aplicación extraterritorial de la ley nacional. ${ }^{21}$ Asimismo, desde el punto de vista procesal, a la prolongación de la detención preventiva y la incomunicación de los procesados, la admisión de nuevos medios de investigación proactivos y encubiertos, testigos ocultos, inversión de la carga de la prueba, órganos judiciales especializados, etc. ${ }^{22}$ En el campo penitenciario, la excepción se manifiesta, principalmente, por la exclusión de algunos beneficios penitenciarios. ${ }^{23}$

${ }^{20}$ Ver, ZAFFARONI, E. R., "Globalización y crimen organizado", Conferencia de clausura de la Primera Conferencia Mundial de Derecho Penal, organizada por la Asociación Internacional de Derecho Pneal (AIDP), Guadalajara (México), 22 de noviembre de 2007, p. 9, disponible en www.cienciaspenales.net; MOCCIA, S., La perenne emergenza. Tendenze autoritarie nel sistema penale, $2^{\mathrm{a}}$ ed., Napoli, Edizioni Scientifiche Italiane, 1997, pp. 53-97; INSOLERA, G., "Nociones de criminalidad organizada...", p. 102. En igual sentido, ZAFFARONI, E. R., El crimen organizado..., p. 4; DONINI, M., Il volto attuale dellillecito penale. La democrazia penale tra differenziazione e sussidiarietà, Milano, Giuffrè, 2004, pp. 53-59; YACOBUCCI, G., "Política criminal y delincuencia organizada", p. 69; Choclán Montalvo, J. A. "Criminalidad organizada. Concepto. La asociación ilícita. Problemas de autoría y participación”, en GRANADOS PÉREZ, C. (Director), La criminalidad organizada. Aspectos sustantivos, procesales y orgánicos, Madrid, Consejo General del Poder Judicial, 2001, p. 219; GÓMEZ DE LIAÑo FONSECA-HERRERO, M., Criminalidad organizada y medios extraordinarios de investigación, Madrid, Colex, 2004, p 45; SILVA SÁNCHEZ, J. M., La expansión del derecho penal..., pp. 159 y ss.; DíEZ Ripollés, J. L., La politica criminal en la encrucijada, Montevideo-Buenos Aires, BdeF, 2007, pp. $147-200$.

21 Véase, entre otros, a ZAFFARONI, E. R., "Globalización y crimen organizado", pp. 9-11; SÁNCHEZ GARCÍA DE PAZ, I., La criminalidad organizada..., pp. 103-215; DE LA CUESTA ARZAMENDI, J. L., "El derecho penal ante la criminalidad organizada...", pp. 97-124; CHOCLÁN Montalvo, J. A., "Criminalidad organizada...", pp. 219-223; ZÚÑIGA RoDRígueZ, L., "Criminalidad de empresa, criminalidad organizada y modelos de imputación penal", en FERRÉ Olivé, J. C. y Anarte Borrallo, E. (Eds.), Delincuencia organizada ..., pp. 199-235.

22 Al respecto, SÁNCHEZ GARCÍA DE PAZ, I., La criminalidad organizada..., pp. 217-286; GÓMEZ DE Liaño FonSECA-Herrero, M., Criminalidad organizada..., pp. 71 y ss.

23 Véase, PAVArini, M., "Lucha contra la criminalidad organizada...", pp. 17-36. Para el caso español, FARALDO CABANA, P., "Medidas premiales durante la ejecución de condenas por terrorismo y delincuencia organizada: consolidación de un subsistema penitenciario de excepción", en CANCio Meliá - Gómez-Jara DíEz (Coordinadores), Derecho penal de enemigo. El discurso penal de la exclusión, vol. 1, Madrid-Buenos Aires-Montevideo, Edisofer-BdeF, 2006, pp. 757-798. 
Sotomayor - Criminalidad organizada y criminalidad económica...

\section{b. El modelo diferenciado en el ámbito de la criminalidad económica}

En el ámbito de la lucha contra la criminalidad económica, el modelo diferenciado se ha ido configurando de la mano de las denominadas propuestas de modernización ${ }^{24}$ del derecho penal, acorde con las demandas derivadas de la denominada sociedad del riesgo. ${ }^{25}$ Entre las características de esta modernización se destacan las siguientes:

1) La existencia de nuevos intereses de carácter universal y nuevos riesgos, que ameritan la intervención penal.

2) Por la aparición de nuevos bienes jurídicos de vago o nulo contenido material, el delito tiende a configurarse como infracción de un deber y no como lesión de un bien jurídico. A su vez, el principio del bien jurídico deja de ser concebido como un límite al legislador y se convierte en una razón para la intervención penal.

3) El derecho penal deja de ser un instrumento de reacción frente a daños y se transforma en instrumento de la política de seguridad, por lo que termina justificándose por sus funciones simbólicas, al no buscar ya la producción de efectos en la realidad sino garantizar la seguridad subjetiva.

4) Se tiende a la protección del contexto, que lleva a una especie de administrativización del derecho penal, por la proliferación de los tipos de peligro abstracto y las leyes penales en blanco.

5) Todo lo anterior se concreta en una relativización de los principios del derecho penal tradicional y la flexibilización de las reglas de la imputación. Al debilitamiento del principio de lesividad hay que agregar el deterioro de la garantía de estricta legalidad, ${ }^{26}$ pues la ley ya no se orienta de forma privativa a la descripción de actos materiales lesivos de bienes jurídicos y verificables empíricamente sino más bien a la descripción de funciones, ${ }^{27}$ Por otro lado, como

\footnotetext{
${ }^{24}$ Sobre este concepto, HASSEMER, W., "Viejo y nuevo derecho penal", AAVV, La responsabilidad por el producto en derecho penal, Tirant lo Blanch, Valencia, 1995, p. 17; igual, ALBRECHT, P. A., "El derecho penal en la intervención de la política populista", p. 476. Sobre la "modernización" del derecho penal, en general y desde diferentes perspectivas, MENDOZA BuERGo, B., El Derecho penal en la sociedad del riesgo, Madrid, Civitas, 2001; SCHÜNEMANN, B., Consideraciones críticas sobre la situación espiritual de la ciencia jurídico penal alemana, Bogotá, U. Externado de Colombia, 1996; SILVA SÁnCHeZ, J. M., La expansión del derecho penal...; Gracia MARTín, L., Prolegómenos para la lucha por la modernización y expansión del Derecho penal y para la crítica del discurso de resistencia, Valencia, Tirant lo Blanch, 2003, pp. 42 y ss.

${ }^{25}$ Cfr. BECK, U., La sociedad del riesgo. Hacia una nueva modernidad, Barcelona, Paidós, 2006, pp. 29-70. Un detallado análisis de las propuestas penales basadas en dicho modelo, en MENDOZA BUERGO, B., El Derecho penal en la sociedad del riesgo, pp. 23 y ss. En Colombia se ha referido al tema, ARIAS Holguín, D. P., A propósito de la discusión..., pp. 17-28.

${ }^{26}$ Cfr. Ferrajoli, L., "Crisi della legalitá e diritto penale minimo", en Curi, U. y PALOMbarini, G. (a cura di), Diritto penale minimo, Roma, Donzelli, 2002, pp. 15 a 18; Suss, F., "El trato actual del mandato de determinación", en INSTITUTO DE CIENCIAS CRIMINALES DE FRANKFURT (ed.), La insostenible situación..., pp. 223 y ss.; MENDOZA BUERGO, B., El derecho penal en la sociedad del riesgo, pp. 95-97.

27 En especial, Moccia, S., "De la tutela de bienes a la tutela de funciones: entre ilusiones postmodernas y reflujos iliberales", en SILVA SÁNCHEZ, J. M. (editor), Política criminal y nuevo Derecho
} 
supuestamente las demandas preventivas no pueden ser satisfechas a través de las categorías propias del derecho penal tradicional, se está procediendo a la revisión de las reglas de atribución de la responsabilidad penal. Es así como la actual dogmática del delito ha comenzado a discutir de nuevo el concepto de acción y los presupuestos personales de la responsabilidad penal, pero buscando ahora abarcar no sólo a las personas físicas o naturales sino también a las personas jurídicas. ${ }^{28}$ Asimismo, el recurso legal a los tipos de peligro abstracto logra obviar las "dificultades" derivadas de la exigencia de una relación de causalidad, ${ }^{29}$ pues el injusto se agota en la creación del peligro objetivo, concepción del injusto que a su vez ha producido una revalorización de las teorías cognoscitivas del dolo, ${ }^{30}$ pues el carácter doloso de un comportamiento depende ahora sólo del conocimiento del riesgo de la acción, con lo que el hasta hace poco esencial elemento volitivo desaparece o en todo caso se le desconecta del resultado.

\section{c. Los riesgos del modelo diferenciado}

No obstante, un importante sector de la doctrina penal ha destacado que la adopción de este modelo diferenciado no está exenta de riesgos, entre los que cabe destacar algunos de especial relevancia:

a. La contaminación del sistema: los riesgos de generalización del modelo penal de excepción a todo el sistema penal. Dado que la estrategia de las recompensas, los beneficios por colaboración, etc., han funcionado en algunos casos, un sistema penal que privilegia los criterios de utilidad difícilmente puede resistir la tentación de extender dicho modelo a todo el sistema penal. En palabras de Pavarini, no se puede ocultar que en la lógica maquiavélica del "fin que justifica los medios" la estrategia podría ser útil: tanto "que la tentación de exportarla a otros sectores de la justicia penal parece difícilmente refrenable. Entreveo, en otras palabras, el grave peligro de que de la 'pena negociada' -como instrumento excepcional en la lucha contra la criminalidad organizada únicamente- pronto se pueda pasar a un 'derecho penal negociante' siempre y en todas las circunstancias". ${ }^{31}$

penal. Libro homenaje a C. Roxin, Barcelona, J. M. Bosch, 1997, pp. 113 y ss.; MENDOZA BuErGO, B., El derecho penal en la sociedad del riesgo, pp. 68 a 78.

${ }^{28}$ Ver ZÚÑIGA RODRígUEZ, L., Bases para un modelo de imputación de responsabilidad penal a las personas jurídicas, $2^{\mathrm{a}}$ edición, Pamplona, Aranzadi, 2003, pp. 55-100.

${ }_{29}$ Al respecto, críticamente, HASSEMER, W., "Rasgos y crisis del derecho penal moderno", en Anuario de Derecho Penaly Ciencias Penales, Madrid, 1992, p. 242; y STELLA, F., Giustizia e modernità. La protezione dell'innocente e la tutela delle vittime, $3^{\mathrm{a}}$ ed., Milano, Giuffrè, 2003, pp. 339-430.

${ }^{30}$ Una síntesis de la discusión, en LAurenzo Copello, P., Dolo y conocimiento, Valencia, Tirant lo Blanch, 1999.

31 PAVArini, M., "Lucha contra la criminalidad organizada...", p. 24. En igual sentido se manifiesta WEIGEND, V. D., "Los sistemas penales frente al reto del crimen organizado", p. 548: "Deberíamos además ser conscientes del hecho de que las nuevas y más eficaces armas que podamos desarrollar, podrán y serán usadas a largo plazo no sólo contra los capos de la droga y las personas que difunden material pornográfico infantil, sino también $-y$ probablemente con mayor frecuencia- en la vida penal cotidiana”. Ampliamente, MoCCIA, S., La perenne emergenza ..., pássim. 
Sotomayor - Criminalidad organizada y criminalidad económica...

b. $\quad$ Subordinación del derecho penal a los intereses procesales. Como explica Donini, "[e]n ningún otro ámbito como el de la lucha, los instrumentos jurídicos parecen destinados a ceder su lugar a reglas instrumentales. El instrumento prevalece sobre las normas de justicia. En este papel, es típico el uso instrumental del proceso a fines de lucha en lugar de investigación. Al proceso penal le incumbe en mucha mayor medida que al Derecho penal sustancial la tarea de gestionar la lucha contra posibles enemigos. Es a través de las investigaciones que aquella lucha se desarrolla en sus formas más evidentes: perquesizioni, secuestros, interceptaciones, confiscación preventiva de bienes, medidas de prevención, medidas cautelares personales, aceleración de los tiempos procesales, atenuación de las garantías probatorias, mecanismos de presión-compensación frente a formas de colaboración, utilización procesal de instituciones materiales (por ejemplo los delitos de asociación ilícita), etiquetamientos personales con consecuencias ejecutivas, penitenciarias, etc., en relación al tipo de procedimientos y de delitos (en realidad son etiquetas de autor): todos éstos son instrumentos de lucha que integran respecto de los bienes agredidos por el proceso (trabajo, familia, honor, patrimonio, salud física y psíquica, libertad de desplazamiento, libertad personal, secretos, ámbitos reservados, etc.) formas de lesión o de puesta en peligro justificadas". ${ }^{32}$

Por consiguiente, es posible que la proliferación de las figuras de la recompensa y los beneficios por colaboración terminen convirtiendo los intereses procesales en el objetivo principal de la intervención penal, a los cuales quedaría subordinado el derecho sustancial, en lo que podría constituir una clara transformación del tradicional papel de ambos, por cuanto el derecho penal sustantivo, a través de la amenaza penal, se convierte en el medio más fácil de lograr la colaboración o confesión del procesado ${ }^{33}$ y en última instancia su condena. En igual medida, "en el tratamiento de los riesgos del mundo moderno con la ayuda del derecho penal, el éxito o finalidad del procedimiento resulta absolutamente prioritario, mientras que el procedimiento en sí mismo y su evaluación desde una óptica distinta del criterio funcional, incluyendo la dimensión del Estado de derecho, pasa ahora en segundo plano". ${ }^{34}$

c. Transformación de los fines de la pena. Lo anterior supone a su vez una transformación de los fines tradicionales de la pena, pues "la entidad adicional de sufrimiento (la detención en una cárcel de máxima seguridad, con prescindencia

\footnotetext{
32 DONINI, M., "El derecho penal frente al 'enemigo", en CANCIO MELIÁ - GÓMEZ-JARA DíEZ (coordinadores), Derecho penal del enemigo..., pp. 651-652. Sobre el tema véase también, del mismo autor, "Non puniblità e idea negoziale", en DONINI, M., Alla ricerca de un disegno. Scritti sulle riforme penali in Italia, Padova, CEDAM, 2003, pp. 370-375.

33 Cfr. Moccia, S., La perenne emergenza ..., pp. 143-199, en especial pp. 190-193; Musco, E., "Los colaboradores de la justicia entre el 'pentitismo' y la calumnia: problemas y perspectivas", en $R P$, 1998 (2), p. 44; PAVARINI, M., "Lucha contra la criminalidad organizada...”, pp. 25-36; DONINI, M., ““'Non puniblità e idea negoziale”, pp. 370-375.

34 Albrecht, H. J., Criminalidad transnacional..., p. 43. Igual, OrSI, O. G., Sistema penal y crimen organizado..., pp. 224-226.
} 
de cualquier evaluación de peligrosidad judicialmente establecida) por la no colaboración, abre a tal punto el abanico de la diferenciación que transforma el sistema carcelario en un instrumento de presión al cual difícilmente se puede resistir durante mucho tiempo. El sistema carcelario se convierte, por consiguiente, en un instrumento inquisitorio para favorecer la colaboración, no diferente en esencia de los premodernos". ${ }^{35}$

d. Posibilidades de instrumentalización política. También la experiencia italiana destaca el hecho de que un sistema como éste no esté exento de los riesgos de manipulación con fines estrictamente políticos, dado que este tipo de colaboración procesal se presta a ser instrumentalizada con objetivos extrajudiciales, que nada tienen que ver con la verificación de la verdad. ${ }^{36}$

\section{La lucha contra la criminalidad organizada en Colombia: el contexto $^{37}$}

Si la realidad de cada país condiciona los contenidos y orienta la aplicación de las normas jurídicas en general, ello es especialmente evidente cuando se trata de conceptos tan vagos e instrumentalizables como el de criminalidad organizada. No debe sorprender, por tanto, que el inciso $2^{\circ}$ del art. 340 del CP colombiano ${ }^{38}$ agrave la figura del "concierto para delinquir" con penas que pueden llegar hasta los dieciocho años de prisión, cuando "sea para cometer delitos de genocidio, desaparición forzada de personas, tortura, desplazamiento forzado, homicidio, terrorismo, tráfico de drogas tóxicas, estupefacientes o sustancias sicotrópicas, secuestro, secuestro extorsivo, extorsión, enriquecimiento ilícito, lavado de activos o testaferrato y conexos, o financiamiento del terrorismo y administración de recursos relacionados con actividades terroristas". Como tampoco que el delito de lavado de activos (art. $323 \mathrm{CP}^{39}$ ) se configure cuando se trata de bienes vinculados

\footnotetext{
35 PAVARINI, M., “Lucha contra la criminalidad organizada...”, pp. 17-36; y FARALDO CABANA, P., "Medidas premiales durante la ejecución de condenas...”, pp. 757-798.

${ }^{36}$ Musco, E., "Los colaboradores de la justicia...", p. 39.

37 En adelante se sigue, en lo fundamental, el análisis realizado en SOTOMAYOR ACOSTA, J. O., "Las recientes reformas penales en Colombia: un ejemplo de irracionalidad legislativa", en DíEZ Ripollés, J. L. - GARCíA PÉREZ, O. (Coordinadores), La politica legislativa penal iberoamericana, Madrid-Montevideo-Buenos Aires, Edisofer-BdeF, 2008 (en prensa).

38 Artículo 240. inciso $2^{\circ}$. Cuando el concierto sea para cometer delitos de genocidio, desaparición forzada de personas, tortura, desplazamiento forzado, homicidio, terrorismo, narcotráfico, secuestro extorsivo, extorsión o para organizar, promover, armar o financiar grupos armados al margen de la ley, la pena será de prisión de seis (6) a doce (12) años y multa de dos mil (2.000) hasta veinte mil (20.000) salarios minimos mensuales legales vigentes.

39 Artículo 323. Lavado de activos. El que adquiera, resguarde, invierta, transporte, transforme, custodie o administre bienes que tengan su origen mediato o inmediato en actividades de extorsión, enriquecimiento ilícito, secuestro extorsivo, rebelión, tráfico de armas, delitos contra el sistema financiero, la administración pública, o vinculados con el producto de los delitos objeto de un concierto para delinquir, relacionadas con el tráfico de drogas tóxicas, estupefacientes o sustancias sicotrópicas, o les dé a los bienes provenientes de dichas actividades apariencia de legalidad o los legalice, oculte o encubra la verdadera naturaleza, origen, ubicación, destino, movimiento o derechos sobre tales bienes, o realice cualquier otro acto para ocultar o encubrir su origen ilícito incurrirá, por esa sola
} 
Sotomayor - Criminalidad organizada y criminalidad económica...

a la realización de ciertos delitos, entre los cuales cabe destacar, junto a los usuales tráfico de drogas, de migrantes o de armas y otros más, delitos como la rebelión, la extorsión, el secuestro y por supuesto el terrorismo, ilícitos cuya inclusión en esta modalidad delictiva se explica fundamentalmente por las particularidades de la realidad colombiana.

Como puede apreciarse, mientras en Europa la lucha contra la criminalidad organizada parece concentrarse de forma prioritaria en el control del tráfico de drogas, el tráfico de personas, el blanqueo de capitales y en general en la criminalidad económica transnacional, ${ }^{40}$ en países como Colombia el énfasis se extiende a formas delictivas más tradicionales, tales como el secuestro, la extorsión, la rebelión, el terrorismo y demás manifestaciones de la conflictividad interna.

Ello, por supuesto, no debe sorprender, pues Colombia vive un conflicto armado de muchísimos años, que si bien no ha impedido la existencia y cierto grado de funcionamiento de las instituciones democráticas y del Estado de Derecho, sí ha creado un contexto de extrema complejidad para el derecho y muy particularmente para el derecho penal, por cuanto no siempre resulta fácil diferenciarlo de la guerra. Unas veces se le utiliza como instrumento de guerra, pero también en otras se le reivindica como herramienta de paz, la cual, en estas circunstancias, deviene más un objetivo a alcanzar por el derecho que un presupuesto de su funcionamiento. ${ }^{41}$ Producto de ello es la permanente sensación de "crisis" del sistema penal, que parece moverse más a los vaivenes propios del conflicto que de los objetivos constitucionales.

Esta conflictividad se ve agravada por la existencia de una criminalidad especialmente violenta relacionada con el tráfico de drogas y por el hecho de que en los últimos años algunos grupos insurgentes recurren a este medio para financiar sus actividades; cosa que también ha ocurrido con los grupos paramilitares de extrema derecha, cuando no es que simples traficantes de drogas terminan conformando grupos paramilitares, quizás con la pretensión de lograr un estatus político que les permita establecer diálogos y negociaciones y obtener luego un tratamiento privilegiado, como se evidenció con la llamada "ley de justicia y paz".

conducta, en prisión de seis (6) a quince (15) años y multa de quinientos (500) a cincuenta mil (50.000) salarios minimos legales mensuales vigentes.

${ }^{40}$ Cfr. BotTKE, W., "Mercado, criminalidad organizada y blanqueo de dinero en Alemania", en RP, 1998 (2), pp. 1 y ss; AlBReCHT, H. J., Criminalidad transnacional..., pp. 11 y ss.; ZúÑIGA RODRíGUEZ, L., "Criminalidad de empresa, criminalidad organizada...", pp. 199 y ss.; SÁNCHEZ GARCÍA DE PAZ, I., La criminalidad organizada..., pp. 46-57; FOFFANI, L., "Criminalidad organizada y criminalidad económica", en $R P, 2001$ (7), pp. 55 y ss.

${ }^{41}$ Véase el completo análisis realizado por APONTE, A., Guerra y derecho penal de enemigo. Reflexión crítica sobre el eficientismo penal de enemigo, Bogotá, Ibáñez, 2006. 
Los resultados saltan a la vista: aunque se ha presentado un descenso en los últimos años, durante 2006 la policía nacional registró un total de 17.479 muertes intencionales, cifra equivalente a una tasa de 38 muertes por cada cien mil habitantes, que aunque lejos de la tasa de 62 alcanzada en 2002 sigue siendo escandalosa, sobre todo si se tiene en cuenta que entre los años 2000 a 2006 los registros oficiales dieron cuenta de 162.497 muertes violentas.

Igual valoración cabe realizar respecto de las cifras referidas al secuestro y la desaparición forzada de personas, pues pese a que también se ha registrado un importante descenso en los últimos años, siguen siendo datos alarmantes. En el período 2002-2006 se supo de 7.630 secuestros según cifras oficiales, y entre 2000-2004 la asociación de familiares de personas desaparecidas (ASFADDES) contabiliza 5.075 casos.

La dramática realidad de la violencia en Colombia queda igualmente retratada en las cifras de desplazamiento forzado interno. Según ACNUR, "[e]1 problema de los desplazados internos en Colombia es una de las situaciones más graves del mundo. El Gobierno de Colombia estima que hay entre 2,5 y 3 millones de Desplazados Internos en el país, siendo 1.796.508 los registrados en el Sistema Único de Registro (SUR), hasta el 30 de abril de 2006. Según datos de la Consultoría para los Derechos Humanos y el Desplazamiento (CODHES) 3.662.842 personas han sido desplazadas por la violencia hasta el 25 de octubre de 2005 y día a día esta cifra aumenta producto de la violencia política asociada al conflicto armado interno". ${ }^{42}$

Como puede apreciarse y así lo señalan algunos analistas, estas cifras corresponden a las de un país en guerra ${ }^{43}$, cualquiera sea el nombre que se le quiera dar. $\mathrm{Y}$ aunque es cierto que en estricto sentido gran parte de la violencia actual no puede atribuirse directamente al conflicto armado, también lo es que en la situación colombiana actual resulta muy difícil trazar una frontera entre la violencia política y aquélla que no lo es, por lo que se puede estimar, con Pecaut ${ }^{44}$, que la violencia puesta en obra por los protagonistas organizados constituye por lo menos el marco de la violencia generalizada existente.

Esta problemática se torna aun más grave cuando se tiene en cuenta la calidad de la respuesta institucional y muy particularmente de la justicia penal, caracterizada por los elevados índices de impunidad, inclusive en los casos graves como los reseñados. Pese a las dificultades que hacen que hoy sea casi imposible

\footnotetext{
42 Véase, http://www.acnur.org/crisis/colombia, donde se pueden consultar, además, cifras e importantes documentos sobre el problema del desplazamiento interno en el país, entre ellos una importante sentencia de la Corte Constitucional (T-025/2004), en la cual declara la situación de los desplazados como un "estado de cosas inconstitucional".

${ }^{43}$ RUBIO, M., "Crimen con misterio. La calidad de la información sobre criminalidad y violencia en Colombia”, Bogotá, CEDE, Universidad de los Andes, 1998 [consultado en: http://economia.uniandes.edu.co], p. 31.

${ }^{44}$ PeCaut, D., "Presente, pasado y futuro de la violencia", en $A P, 1997$ (30), p. 1.
} 
Sotomayor - Criminalidad organizada y criminalidad económica...

saber la verdadera magnitud de la impunidad en Colombia, ${ }^{45}$ los analistas coinciden en que ésta no sólo es muy alta sino persistente. ${ }^{46}$ Para el caso del homicidio, según Rubio, "[1]a probabilidad de que un homicidio sea condenado, del $11 \%$ en los sesentas apenas sobrepasa en la actualidad el $4 \%$ " ${ }^{47}$ Como es de suponer, la situación no es más alentadora cuando se mira hacia el secuestro, la desaparición forzada y otros hechos de similar gravedad. ${ }^{48}$

Lo anterior ha derivado en una profunda crisis del sistema de justicia penal en Colombia, que por tal motivo se ha visto sometido a permanentes reformas de muy diferentes signos, como lo refleja con claridad la profusa producción legislativa de carácter penal de los últimos años.

$\mathrm{Al}$ no reconocerse la naturaleza del conflicto, de forma equivocada se ha buscado una solución jurídico-penal al problema de la guerra, con todas las consecuencias negativas que ello representa, tanto desde el punto de vista del conflicto como de la justicia penal, pues por supuesto el primero no se resuelve por la vía penal y la segunda se ve instrumentalizada como arma de guerra.

Aunque los problemas son múltiples, destaca la falta de capacidad investigativa de la justicia penal, pues un número importante de delitos no logran siquiera superar la fase de investigación previa, inclusive tratándose del homicidio, dado que la policía se muestra inoperante en su función principal de prevención y control de la criminalidad, porque preparados para la lucha contrainsurgente y la persecución de las grandes mafias del narcotráfico, los órganos de investigación

45 Restrepo, E. M. y Martínez CuÉllar, M., "Impunidad penal: mitos y realidades", Documento CEDE 2004-4, Bogotá, Universidad de los Andes, 2004 [consultado en http://economia.uniandes.edu.co]; UPRIMNY, R., "La justicia colombiana en la encrucijada", p. 2, en http://www.djs.org.co [consultado el 21/06/2007].

46 En general sobre el tema y desde distintos puntos de vista, entre otros, PECAUT, D., "Presente, pasado y futuro...", pp. 34-36; Restrepo, E. M. y MARTíneZ CuÉLlar, M., "Impunidad penal...”, pássim; UPRIMnY R., "La justicia colombiana...”, p. 2; RUBIO, M, “Crimen sin sumario. Análisis económico de la justicia penal colombiana", Bogotá, CEDE, Universidad de los Andes, 1998, en http://economia.uniandes.edu.co [consultado el 27/06/2007], pp. 11 y ss.; RODRíGUEZ, C., UPRIMNY, R. y GARCíA VilLEGAS, M., "Entre el protagonismo y la rutina: análisis sociojurídico de la justicia en Colombia", pp. 44-49, en http://www.djs.org.co [consultado 21/06/2007]; GAITÁN DAZA, F., "Multicausalidad, impunidad y violencia: una visión alternativa", en REI, 2001 (5), pp. 78-105.

47 RUBIO, M., "Crimen sin sumario...", p. 40.

${ }^{48}$ Cfr. Restrepo, E. M., SÁnchez TORres, F. y MartíneZ, M., “¿Impunidad o castigo? Análisis e implicaciones de la investigación penal en secuestro, terrorismo y peculado”, Bogotá, Documento CEDE 2004-09, Universidad de los Andes, 2004, pp. 1-39, en http://economia.uniandes.edu.co [consultado el 27/06/2007]; CCJ, "Colombia: 2002-2006: situación de derechos humanos y derecho humanitario", [consultado en http://www.coljuristas.org], pp. 1-13; ACNUDHC, "Informe de la Alta Comisionada de las Naciones Unidas para los Derechos Humanos sobre la situación de los derechos humanos en Colombia", 2006 [consultado en http://www.hchr.org.co], pp. 5-27. 
policial resultan muy poco eficaces en la protección de los ciudadanos y en la investigación y persecución penal. ${ }^{49}$

Tal situación está produciendo lo que con carácter general algunos denominan proceso de trivialización del sistema judicial colombiano, ${ }^{50}$ que en el caso de la justicia penal se concreta en que ésta sólo parece funcionar en aquellos casos de muy pocas exigencias probatorias (tal como sucede en los casos de flagrancia y del pequeño comercio callejero de drogas, lesiones y homicidios en accidentes de tránsito, etc.), o de cierta clase de delitos en los que el imputado es identificado desde un comienzo (como sucede en la inasistencia alimentaria, violencia intrafamiliar, etc.). Por el contrario, los casos delincuenciales en los que se desconoce al posible autor difícilmente llegan a ser resueltos, independientemente de la gravedad del delito.

Lo más grave es que también en el plano formal el sistema se ha ido acomodando a esta situación y poco a poco se han comenzado a introducir mecanismos legales que intentan compensar el déficit de investigación existente con beneficios por confesión, sentencia anticipada (o aceptación de cargos), negociación de penas, al tiempo que crece la utilización indiscriminada del sistema de las recompensas. De esta manera se ha ido institucionalizando un sistema procesal penal de corte eficientista, que a su vez está generando una negativa influencia en el derecho penal sustantivo y a lo que mucho parecen estar contribuyendo las recientes reformas procesales.

\section{Consecuencias de la lucha contra la criminalidad organizada en el sistema penal colombiano}

Una situación tan problemática como la descrita por supuesto repercute de manera directa en el aparato de justicia penal, por lo que no es de extrañar que en el sistema penal colombiano se hagan realidad muchos de los que en otros contextos se denuncian como meros riesgos del modelo de la excepción en la lucha contra la criminalidad organizada.

\footnotetext{
$49 \mathrm{Al}$ respecto, APONTE, A., Guerra y derecho penal de enemigo...pp. 486-519. Destaca la militarización y deficiencias de la policía colombiana, Guerrero Peralta, O. J., "La policía en el Estado de Derecho latinoamericano: el caso Colombia”, en Ambos, K., GÓMEZ COLOMER, J. L. y VoGLER, R. (editores), La policia en los estados de derecho latinoamericanos: un proyecto internacional de investigación, Bogotá, Gustavo Ibáñez, 2003, pp. 195-237; también, GORDON ATEHORTúA, L. y KuRY, H., "Victimización como hecho cotidiano. Un estudio victimológico en Colombia", en RDPC, 2006 (18), pp. 403-407.

${ }^{50}$ RodrígueZ, C., Uprimny, R. y García Villegas, M., "Entre el protagonismo y la rutina...", pp. 48-49.
} 
Sotomayor - Criminalidad organizada y criminalidad económica...

\section{a. La legislación penal colombiana: de la excepción a la regla}

En el contexto ya expuesto resultaba difícil que un Estado sumido en una "crisis" permanente, con una justicia penal con un bajísimo nivel de eficacia, resistiera la tentación de extender de manera paulatina el modelo de lucha contra el crimen organizado a todo el sistema penal. Una somera mirada a la evolución de la legislación penal resulta suficiente para comprobar que unas normas en su momento previstas como medidas especiales en la lucha contra los carteles de la droga pasaron, primero, de legislación temporal del antiguo régimen de estado de sitio conforme a la Constitución de 1886, a legislación permanente de acuerdo con la Constitución de 1991, como fue el caso de los muy relevantes decretos 180 de 1988 y 2790 de $1990^{51}$. Asimismo, con la aprobación de la amplia reforma penal de 2000, que incluyó la expedición de un nuevo código penal (ley 599 de 2000) y un nuevo código de procedimiento penal (ley 600 de 2000), a iniciativa del fiscal general de la nación de aquel entonces, tuvo lugar a su vez la conversión en legislación ordinaria, de la gran mayoría de normas aprobadas como excepcionales, al fragor de la lucha contra el terrorismo y el tráfico de drogas. Entre ellas las referidas a los beneficios por colaboración con la justicia, inicialmente previstos en el art. 63 del decreto 2790 de 1990 sólo para los delitos de competencia de la denominada en aquel entonces "justicia regional" (antes "de orden público" y hoy "especializada"), y que el nuevo CPP convirtió en regla general aplicable a todos los delitos y en todo momento, los cuales se agregaron a las ya extendidas rebajas de pena por sentencia anticipada (art. 40 CPP) y confesión (art. 283).

Esta generalización de los beneficios por colaboración se vio confirmada y ampliada mediante la expedición de la ley 906 de 2004 que instauró en Colombia el proceso penal acusatorio, puesto que el nuevo estatuto no sólo consagró la rebaja de pena (hasta la mitad) por aceptación de cargos (art. 351), sino también la posibilidad de celebrar acuerdos y negociaciones entre la fiscalía y el imputado o acusado (art. 350); asimismo, consagró el principio de oportunidad, entre otros eventos, "Cuando el imputado colabore eficazmente para evitar que continúe el delito o se realicen otros, o aporte información esencial para la desarticulación de bandas de delincuencia organizada" (art. 324-5). Llama la atención, no obstante, que el parágrafo 3 de este mismo artículo excluye la aplicación del principio de oportunidad si se trata, entre algunos otros, de los delitos de narcotráfico y terrorismo. La paradoja no podría ser mayor: medidas premiales que en Colombia surgieron como excepcionales herramientas de lucha contra la criminalidad violenta generada por el narcotráfico, terminaron reconociéndose de forma general para todos los delitos, salvo para aquéllos que en su momento se alegaron como motivos para su creación. Paradoja que quizás se explique por el hecho que en Colombia, en realidad, las dificultades de investigación y esclarecimiento de los delitos no se circunscriben a la delincuencia organizada transnacional, sino que, por las razones atrás comentadas, se extienden prácticamente a todo tipo de

\footnotetext{
${ }^{51}$ Con amplitud, APONTE, A., Guerra y derecho penal de enemigo..., pp. 292 y ss.
} 
criminalidad, por lo que la generalización resultaba más que previsible en tales circunstancias. El hecho de que luego hayan terminado excluidos de dichos beneficios algunos de los destinatarios originarios de los mismos, quizás tenga que ver con la más reciente política gubernamental de suprimir todo tratamiento que de manera directa o indirecta pudiera beneficiar a los movimientos insurgentes. Por tanto, la utilización (y no utilización) de la justicia "premial", se encuentra condicionada más por la lógica de la confrontación interna, que por el control efectivo de formas de criminalidad transnacional.

\section{b. Subordinación del derecho penal sustantivo al proceso: la creciente autonomia del proceso penal como mecanismo de control social}

Uno de los rasgos más característicos de la evolución reciente del sistema penal colombiano es el de la creciente autonomía del proceso penal como mecanismo de control social, frente al cual el derecho penal sustancial deviene ahora un simple medio. A dicha inversión de las funciones tradicionales del proceso mucho ha contribuido el rol asumido desde su creación por la fiscalía general de la nación, pues, en medio de una notable precariedad investigativa estatal, la fiscalía surge como respuesta a los desafíos de las mafias del narcotráfico, lo cual implicó desde las reformas de 1991 una desmedida acumulación de poderes, hasta el extremo que su actividad se convirtió en eje de la justicia penal y generadora de una ideología que trasciende el ámbito estrictamente judicial. En efecto, de la mano de un manejo ligero e irresponsable de los asuntos atinentes a la criminalidad por parte de los medios de comunicación, una fiscalía que también cumplía funciones jurisdiccionales como la de ordenar capturas, allanamientos, detenciones, entre otras, terminó asumiendo un rol casi policivo de "lucha contra la criminalidad", lo cual no sólo al interior de la institución misma sino en el imaginario social, terminó reduciendo la justicia penal a la actuación de su ente investigador; luego, una detención comenzó a ser vista como la satisfacción del objetivo penal y una libertad provisional (es decir, sin levantamiento de los cargos) pasó a ser percibida como sinónimo de fracaso e impunidad. ${ }^{52}$

Y si bien la instauración del sistema acusatorio (ley 906 de 2004) despojó a la fiscalía de los poderes jurisdiccionales de que antes disponía (entre ellos los de decretar allanamientos, capturas y detenciones), recientemente se expidió la ley 1142 de 2007 con la única pretensión de facilitar la detención en el sistema acusatorio, quizás como reacción a la posición un poco más estricta (al menos en comparación con la que tenían los propios fiscales conforme al sistema anterior) que al respecto han asumido algunos jueces de garantías, de conformidad con las exigencias de la jurisprudencia constitucional. Pero no se crea que se trata de un objetivo oculto o algo por el estilo; todo lo contrario, la propuesta presentada conjuntamente por el ministro del interior y el fiscal general de la nación

\footnotetext{
52 Sobre el particular, Grosso García, M. S., La reforma del sistema penal colombiano, Bogotá, Gustavo Ibáñez, 1999.
} 
Sotomayor - Criminalidad organizada y criminalidad económica...

reivindica abiertamente tal ideología, hasta el extremo de calificar como "impunidad" la no imposición de la detención preventiva:

“... el presente Proyecto tiene como finalidad brindar herramientas político criminales para luchar de manera eficaz contra las conductas punibles que afectan de manera notoria la convivencia y seguridad ciudadana, evitando con ello que se cercene la confianza de los ciudadanos en la administración de justicia. Así, en aras de combatir la impunidad, se hace necesario que las personas que cometan delitos que atentan contra la seguridad y tranquilidad ciudadana sean recluidas en centros carcelarios; que respondan con sus bienes por los perjuicios que ocasionan a las víctimas y que en caso de condena cumplan la totalidad de la pena. Por ello, también se reforman algunos artículos de la ley 599 de 2000 (Código Penal) para aumentar las penas de manera que pueda imponerse como medida de aseguramiento la de detención preventiva". ${ }^{53}$

Como es apreciable, todo esto demuestra el protagonismo casi absoluto de la detención preventiva como objetivo concreto de la persecución penal, que la está convirtiendo en un equivalente funcional de las medidas de seguridad predelictuales, con un claro predominio de las nociones de peligrosidad y defensa social. $^{54}$

A su vez, este predominio de la detención preventiva está propiciando de manera indirecta un generalizado y desmesurado incremento del mínimo de las penas, toda vez que los dos códigos de procedimiento penal vigentes (leyes 600/2001 y 906/2004), hacen depender la procedencia de la detención preventiva de que el delito imputado tenga una pena mínima igual o superior a los 4 años de prisión; cosa parecida ocurre con la detención domiciliaria, que sólo procede por delitos sancionados con una pena mínima de 5 años. Pues bien, para obligar a la detención preventiva (o evitar la procedencia de la detención domiciliaria) en desarrollo de la tendencia legislativa que se comenta, el legislador penal colombiano ha optado por el camino más fácil: ha aumentado la pena mínima de los delitos hasta el tope exigido por la ley procesal para imponer la medida cautelar. El resultado: un inimaginable endurecimiento punitivo con fines exclusivamente procesales.

\footnotetext{
53 Véase la exposición de motivos de los autores de la iniciativa, el ministro del interior y el fiscal general de la nación, en GC, 2006 (250) [consultada en: http://www.secretariasenado.gov.co].

54 Cfr. Hernández, T., La ideologización del delito y de la pena, Caracas, Universidad Central de Venezuela, 1977; Terradillos, J., Peligrosidad social y Estado de Derecho, Madrid, Akal, 1981; y Sotomayor Acosta, J. O., Inimputabilidad y sistema penal, Bogotá, Temis, 1996, pp. 119-129.
} 
Las consecuencias de esta política son bastante previsibles: según datos del INPEC $^{55}$ a mayo de 2007 (los cuales no reflejan todavía los efectos de la ley 1142 de 2007) había un total de 60.139 reclusos en Colombia, de los cuales 43.657 tienen la calidad de detenidos, es decir, el $72.59 \%$; además, los altos índices de hacinamiento carcelario han empezado ya a disparar las alarmas de los organismos internacionales de defensa de los derechos humanos y de algunas instituciones estatales. ${ }^{56}$

Claro que el amplio número de detenidos no es ninguna novedad en los sistemas penales latinoamericanos ${ }^{57}$ y muchos menos en el colombiano. ${ }^{58}$ Lo nuevo está en que en los últimos años las normas penales sustantivas colombianas se han ido acomodando a esta realidad, hasta el punto que hoy en día la fijación de la pena abstracta de una figura delictiva por parte del legislador, no se hace con base en los tradicionales criterios del merecimiento y necesidad de pena sino en atención a su repercusión sobre los presupuestos de la detención preventiva o la libertad provisional, o inclusive la detención domiciliaria, de conformidad con las normas procesales vigentes.

\section{c. Transformación de los fines de la pena: la condena sin proceso}

Lo anterior supone, como ya se ha dicho, una clara transformación de los tradicionales fines de la pena, pues la amenaza penal no pretende ya disuadir o persuadir a la colectividad de que se abstenga de delinquir, y mucho menos las penas se calculan o imponen de conformidad con las exigencias de una pena orientada al tratamiento. Se trata sólo de que el procesado confiese o colabore con la justicia, tal como sucedió con algunos delitos contra la administración de justicia (entre ellos el falso testimonio), cuyas penas mínimas se incrementaron a los 4 ó 6 años con la sola finalidad de hacer posible la detención preventiva o de excluir la libertad provisional o la detención domiciliaria (ley 890/2004). En esta misma línea se deben mencionar la ley $813 / 2003$ en relación con el hurto de

\footnotetext{
55 Dichas cifras se pueden consultar en http://www.inpec.go.co, aunque debe aclararse que el INPEC manipula las cifras al presentar diferenciados el número de sindicados, condenados en primera instancia y condenados en segunda instancia, cuando sólo los últimos tienen la calidad de condenados.

56 Consultar los informes de la ACNUDHC, "Centros de reclusión en Colombia: un estado de cosas inconstitucional y de flagrante violación de derechos humanos", informe del 31 de octubre de 2001 [disponible en: http://www.hchr.org.co]; DEFENSORÍA DEL PuEBLO, "Análisis sobre el actual hacinamiento carcelario y penitenciario en Colombia", Bogotá, 2003, consultado en http://www.defensoria.org.co; y PROCuRAduría GENERAL DE LA NACiÓN, "El sistema de prisiones colombiano opera bajo niveles de presión crecientes; los derechos humanos de las personas privadas de libertad en riesgo", en http://www.procuraduria.gov.co [consultado 16/07/2007].

${ }^{57}$ Cfr. Carranza, E. y otros, El preso sin condena en América Latina y el Caribe, San José, ILANUD, 1998.

58 Al respecto la sentencia T-153/1998, en la cual la Corte Constitucional declaró la situación de las cárceles colombianas como un "estado de cosas inconstitucional".
} 
Sotomayor - Criminalidad organizada y criminalidad económica...

automotores, que con ese fin pasó de considerarse un supuesto de hurto agravado (art. 241-6) a convertirse en un caso de hurto calificado (o robo); la ley 1028/2006, que incluyó el delito autónomo de hurto de hidrocarburos en el CP (antes incluido en la temporal ley 782/2002); un aumento de penas en el mismo sentido se hizo mediante la ley 1032/2006 para algunos delitos como la prestación, acceso o uso ilegal de los servicios de comunicaciones (art. 257), violación de derechos patrimoniales de autor y otros (art. 271) y usurpación de derechos de propiedad industrial y de obtentores de variedades vegetales (art. 306).

Lo mismo sucede con la más amplia y reciente ley 1142/2007, cuyo solo nombre es indicativo de la ideología que inspira su contenido: "Ley de convivencia y seguridad ciudadana". Entre los muchos aspectos retrógrados de esta ley hay dos especialmente destacables: la reforma de algunos tipos y en especial el aumento considerable de la pena mínima (entre los 4 y los 6 años), con el objetivo ya indicado, en delitos como la inasistencia alimentaria, hurto calificado, hurto agravado, receptación, delitos electorales, porte de armas y otros más. Por otro lado, con idéntica finalidad se reforma el CPP en cuanto a los criterios a tener en cuenta para imponer la detención preventiva; y aunque el Congreso finalmente no aprobó la propuesta original de establecer un catálogo de delitos en los cuales "se presume el peligro para la comunidad" (art. 20 del proyecto original), de todas maneras la reforma reduce los poderes del juez de garantías y sobre todo exime a la fiscalía del deber de acreditar ante el juez los presupuestos materiales que justifican su solicitud de detención preventiva.

De todas maneras, la expedición de la ley 890 de 2004 es la que mejor retrata la mencionada transformación de los fines de la pena en Colombia, ya que mediante esta ley se aumentó la pena de prisión hasta un máximo de 60 años en caso de concurso de delitos y hasta los 50 para delitos en particular (arts. 1 y 2). Pero lo verdaderamente increíble fue el aumento generalizado de penas previsto en el art. 14, que ordenó para todos los delitos un incremento de la pena mínima en una tercera parte y del máximo en la mitad. Si un aumento generalizado de penas como éste es en sí mismo cuestionable en un país cuyo sistema de penas no se caracteriza precisamente por su moderación, el asunto raya en lo demencial cuando se conocen los motivos tenidos en cuenta para proponer y aprobar dicho incremento: la negociación y preacuerdos de pena entre la fiscalía y el procesado, tal como se reconoce en la exposición de motivos y se recoge en la ponencia primer debate en el senado de la república:

"La razón que sustenta tales incrementos está ligada con la adopción de un sistema de rebaja de penas (materia regulada en el Código de Procedimiento Penal) que surge como resultado de la implementación de mecanismos de 'colaboración' con la justicia que permitan el desarrollo eficaz de las investigaciones en contra de grupos de delincuencia organizada y, al mismo tiempo, aseguren la imposición 
de sanciones proporcionales a la naturaleza de los delitos que se castigan" $"$.

Se trataba simple y llanamente de "aceitar" de manera adecuada la máquina eficientista de producción de condenas en que desde un comienzo se ha querido convertir el proceso acusatorio, para lo cual se requería entonces disponer de unas penas lo suficientemente altas para constreñir al imputado a negociar o a la aceptación de cargos. O simplemente con el argumento de que al finalizar las rebajas la pena siga siendo de alguna manera proporcional al delito cometido. ${ }^{60}$

Todo indica, además, que la estrategia ha sido exitosa, como parecen corroborarlo los primeros datos que se conocen sobre el funcionamiento del sistema acusatorio, tanto en su fase I (Bogotá y eje cafetero) como en la fase II (Medellín, Valle y otros), según se puede apreciar en las siguientes gráficas. ${ }^{61}$

Gráfica 1: Porcentaje de sentencias condenatorias

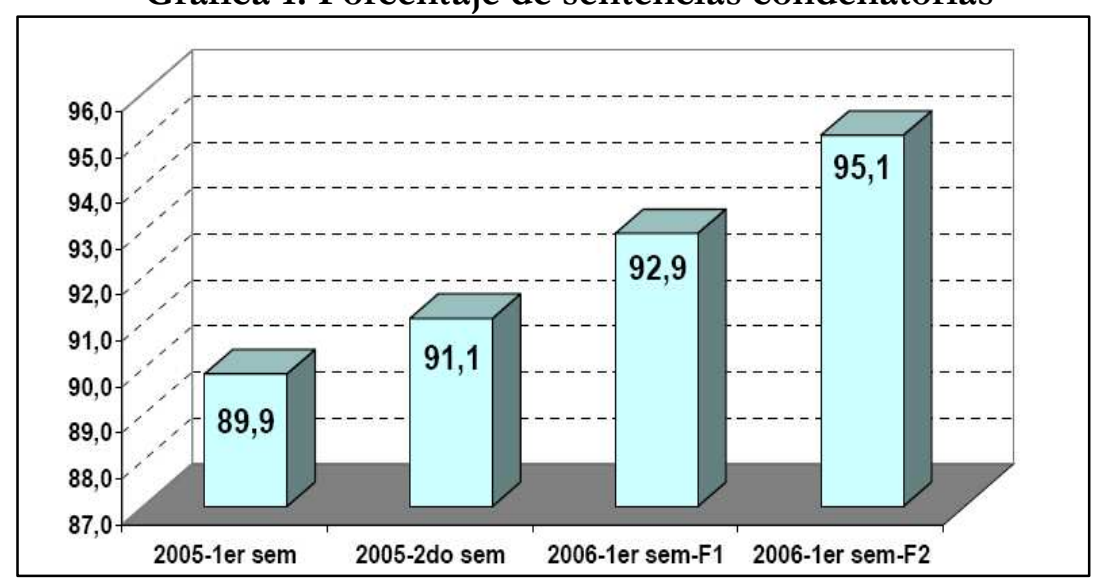

Fuente: CEJOSPA

59 "Exposición de motivos", en GC, 2003 (345) [consultada en: http://www.secretariasenado.gov.co].

${ }^{60}$ Véase la intervención en tal sentido del representante Navas Talero, ponente del proyecto, en la plenaria de la Cámara de Representantes, en GC, 2004 (391), [consultada en http://www.secretariasenado.gov.co]. Pese a la irracionalidad tanto de las medidas adoptadas como de los argumentos, la ley ha superado en términos generales las evaluaciones de la Corte Constitucional (sentencias C-193/2005, C-194/2005, C-823/2005, entre otras). Con una agravante adicional: la ley 890/2004, a diferencia de lo ocurrido con el sistema acusatorio (ley 906/2004) cuya implementación ha sido gradual, entró a regir de inmediato en todo el país, con lo cual las penas se aumentaron para todos los delitos y en todo el territorio, aun cuando los hechos fueran juzgados conforme a la ley 600/2000, que no prevé posibilidad de negociación entre fiscalía y defensa y que consagra para la sentencia anticipada una rebaja de pena menor a la del nuevo CPP; situación que ha dado lugar a graves problemas de aplicación práctica, por la evidente desigualdad punitiva entre las personas juzgadas conforme al "viejo" y el "nuevo" sistema procesal. Cfr. CSJ, sentencias de 14/12/2005 y 7/02/2006.

${ }^{61}$ Tomadas de CEJ, "Observatorio ciudadano del sistema acusatorio", pp. 45 y 54, en http://www.cej.org.co. 
Gráfica 2: Porcentaje de sentencias con aceptación de cargos

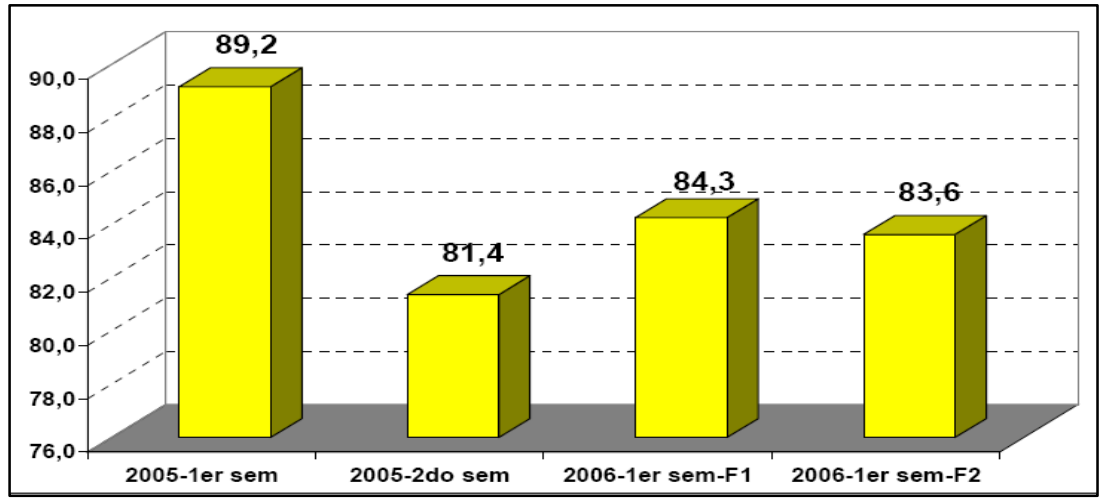

Según estos datos, el nuevo sistema penal acusatorio ha comenzado a funcionar como una máquina de producción de condenas, con lo cual, en razón del alto porcentaje de sentencias con aceptación de cargos (como puede apreciarse en la gráfica 2), el sistema está cumpliendo a cabalidad con el objetivo para el que al parecer fue creado: producir condenas sin proceso. ${ }^{62}$

No obstante, si el objetivo de extender la justicia "premial" a todos los delitos era mejorar los índices de eficiencia del sistema, y en especial en lo atinente a la criminalidad más grave, se puede anticipar un nuevo fracaso, pues como el problema de la justicia penal colombiana es estructural y no de las formas del proceso o de configuración formal de la ley sustantiva, lo que parece estar sucediendo es simplemente la acomodación del nuevo sistema acusatorio a la realidad existente. No ha habido cambios en los resultados pues al igual que el "viejo sistema" en la práctica el sistema acusatorio sólo está funcionando para los casos de flagrancia o con imputado conocido, es decir, para los casos más fáciles de resolver desde el punto de vista investigativo, como puede apreciarse en los datos que suministra el Consejo Superior de la Judicatura:

\footnotetext{
62 Así por lo demás lo expresa la gran impulsora e ideóloga de la reforma, la Corporación Excelencia en la Justicia, en CEJ, “Observatorio ciudadano...", p. 46: "El 80\%, aproximadamente, de sentencias con aceptación de cargos representa un gran avance en comparación con la proporción de sentencias anticipadas en el sistema anterior que sólo alcanzaba el 29\%. Este resultado indica que el modelo se está desarrollando de la manera en que fue concebido pues se esperaba que un alto número de procesos concluyera de esta manera" (cursivas fuera de texto).
} 
Tabla 4: Delitos ingresados (sistema acusatorio) Enero 2005 Agosto 2006

\begin{tabular}{|l|c|r|}
\hline \multicolumn{1}{|c|}{ Delito } & \multicolumn{1}{c|}{$\%$} & CASOS \\
\hline Hurto & $36,90 \%$ & 23.017 \\
\hline Lesiones Personales & $12,10 \%$ & 7.548 \\
\hline Fabricación importación y tráfico de armas & $11,80 \%$ & 7.361 \\
\hline Tráfico y consumo de estupefacientes & $6,00 \%$ & 3.743 \\
\hline Homicidio & $4,60 \%$ & 2.869 \\
\hline Falsedad & $4,30 \%$ & 2.682 \\
\hline Receptación & $3,40 \%$ & 2.121 \\
\hline Sexuales & $2,60 \%$ & 1.622 \\
\hline Defraudación derechos autor & $1,80 \%$ & 1.123 \\
\hline Estafa & $1,39 \%$ & 867 \\
\hline Fabricación, tráfico, porte e prendas uso FFMM & $1,32 \%$ & 823 \\
\hline Daño bien ajeno & $1,23 \%$ & 767 \\
\hline Inasistencia alimentaria & $1,10 \%$ & 686 \\
\hline Extorsión & $0,80 \%$ & 499 \\
\hline Violencia intrafamiliar & $0,75 \%$ & 468 \\
\hline Secuestro & $0,70 \%$ & 437 \\
\hline Concierto para delinquir & $0,69 \%$ & 430 \\
\hline Violencia contra servidor público & $0,54 \%$ & 337 \\
\hline Otras & $7,98 \%$ & 4.978 \\
\hline Total & $\mathbf{1 0 0 , 0 0 \%}$ & $\mathbf{6 2 . 3 7 8}$ \\
\hline
\end{tabular}

Fuente: Consejo Superior de la Judicatura.

En otras palabras, el sistema se muestra especialmente eficiente con la criminalidad de bagatela, ${ }^{63}$ frente a la cual la verdad es que todos los sistemas penales suelen funcionar demasiado bien. Por el contrario, el problema de fondo, es decir, la debilidad investigativa generalizada y muy particularmente frente a las manifestaciones más graves de la criminalidad se mantiene intacta. No es de extrañar, en consecuencia, que a menos de dos años de su puesta en vigencia el sistema ya presente importantes signos de congestión en la fase de indagación, ${ }^{64}$ tal como sucedía en el sistema anterior. Por ello es de temer que el afán eficientista por mostrar resultados inmediatos ponga en riesgo algunos evidentes logros del sistema en materia de garantías procesales, cuya realización efectiva presupone la existencia de proceso, que es lo que casi no hay todavía.

A esta máquina eficientista hay que sumarle el nuevo motor que en tal sentido puede significar el principio de oportunidad (arts. 321 a 330), que pese a

63 Así lo corroboran los datos del CONSEJO SuPERIOR DE LA JUDiCATURA, "Sistema penal acusatorio. 2 años de expedición del código de procedimiento penal", Documento SA-0101, pp. 13-14 [disponible en www.ramajudicial.gov.co].

${ }^{64}$ Como informa la CEJ, “Observatorio ciudadano...", p. 52. 
Sotomayor - Criminalidad organizada y criminalidad económica...

su todavía escasa aplicación ${ }^{65}$ amenaza con aumentar aún más la selectividad del sistema penal colombiano, con el riesgo adicional que un mecanismo como este supone en un país en el que la utilización (y no utilización) estatal del derecho penal con fines políticos no es ninguna novedad. ${ }^{66}$

\section{d. Instrumentalización politica}

La anterior no es la única selectividad apreciable del sistema penal colombiano, pues se presenta otra por lo menos igual de odiosa, que refleja muy bien el uso político que puede hacerse de algunos de los mecanismos surgidos en la lucha contra la criminalidad organizada. Se trata de la expedición de la conocida como "ley de justicia y paz". Esta ley fue producto del proceso de negociación del gobierno del presidente Uribe Vélez con algunos grupos paramilitares y pese a que la Corte Constitucional, mediante la sentencia C-306/2006, declaró la inconstitucionalidad (o la constitucionalidad condicionada) de algunas de sus disposiciones más polémicas, se teme que genere la impunidad de graves violaciones a los derechos humanos, dado que con el procedimiento previsto será prácticamente imposible llevar a cabo una investigación que vaya más allá de los hechos que las personas involucradas hayan querido confesar. En efecto, ya se comentó que la debilidad investigativa del Estado colombiano constituye uno de los mayores problemas de su aparato de justicia penal, por el gran número de delitos graves que no alcanza a superar la fase de investigación previa; pues si eso es así en el campo de la justicia ordinaria, no se puede esperar que en un lapso de tiempo mucho más breve y sin recursos técnicos ni humanos se puedan esclarecer dolorosos episodios que no han podido investigarse durante años, ${ }^{67}$ la mayoría de las veces ocurridos en regiones muy apartadas de las ciudades donde se realizan los "juicios".

Que de un trámite casi administrativo como el previsto en la ley puedan derivarse amnistías e indultos para quienes no tengan procesos judiciales abiertos o condenas, o para quienes sólo puedan ser acusados de delitos políticos (rebelión, sedición y asonada), concierto para delinquir, utilización ilegal de uniformes e insignias, instigación a delinquir, o fabricación, tráfico y porte de armas y

\footnotetext{
${ }^{65}$ Según los datos de CEJ, "Observatorio ciudadano...", p. 40, entre enero de 2005 y junio de 2006, se ha dado aplicación al principio de oportunidad en 904 ocasiones.

${ }^{66}$ Llama la atención sobre este aspecto, CALlE CALDERÓn, A. L., "Acerca de la reforma procesal penal. Una primera aproximación”, en NFP, 2005 (67), pp. 162-165.

67 En este sentido, GONZÁlEZ ZAPATA, J., "Verdad, justicia, paz y reparación en la mitología penal. A propósito de la ley 975 de 2005”, en EP, 2005 (27), p. 50; así también lo han manifestado, HRW, "Colombia: librando a los paramilitares de sus responsabilidades", enero de 2005 [disponible en http://www.hrw.org]; Amnistía Internacional, "Colombia: la Ley de Justicia y Paz garantizará la impunidad para los autores de abusos contra los derechos humanos", abril 26 de 2005 [disponible en http://www.amnesty.org]; ACNUDHC, "Consideraciones sobre la ley de 'Justicia y Paz", junio 27 de 2005; CCJ, "Sin paz y sin justicia”, Boletín No. 6, junio 29 de 2005; $\mathrm{CIDH}$, "La CIDH se pronuncia frente a la aprobación de la ley de justicia y paz en Colombia", julio 15 de 2005 [los tres últimos documentos están disponibles en http://www.coljuristas.org].
} 
municiones (art. 69), parece más propio del tipo de leyes de "perdón y olvido". Pero además, el hecho de que algunos de los más graves crímenes cometidos por los grupos paramilitares puedan terminar con una pena máxima de 7 años de prisión no deja de entrañar una gravísima desigualdad y desproporcionalidad, cuando al tiempo que el gobierno impulsaba la aprobación de esta ley, presentaba al Congreso las ya mencionadas leyes de incrementos punitivos, ${ }^{68}$ entre ellas la ley 890/2004 que aumentó los mínimos y máximos de las penas para todos los delitos y después la ley 1142/2007, que entre otras disposiciones aumenta la pena del hurto calificado por la violencia contra las personas, de 8 a 16 años de prisión (art. 37). Que un ladronzuelo que realiza un hurto callejero con intimidación pueda recibir más del doble de pena que los autores de algunos de los hechos más dolorosos de la reciente historia nacional (homicidios colectivos, la mayoría de ellos en condiciones de indefensión de la víctima, desmembración de cuerpos, desapariciones de personas y un largo etcétera) es algo tan desproporcionado que jurídicamente resulta muy difícil de justificar.

Si el logro de la paz legitima o no este tipo de leyes es un interrogante realmente complejo, que no puede tener una respuesta sin matices. El problema de la ley 975/2005 es que ella ni siquiera supone el logro de la paz, pues "se trata de una ley que se expide no al final sino en medio de la guerra", ${ }^{69}$ a lo cual habría que agregar el hecho de no implicar ni siquiera el desmonte real y efectivo de las estructuras paramilitares, dado que permite la desmovilización individual, sin que ella signifique ningún compromiso respecto de las organizaciones armadas respectivas. $^{70}$

Todo parece indicar que esta ley constituye más bien un nuevo uso de la legislación penal como mecanismo de guerra, porque cabe recordar que ello se puede dar por la utilización por parte del Estado tanto de mecanismos positivos como negativos; vale decir, tanto cuando se usa la ley para golpear directamente al adversario, como también cuando a través de la ley se crean mecanismos que aseguran inmunidad frente al sistema penal institucional, bien de los propios agentes estatales o de sus aliados, a través de instrumentos tales como la justicia penal militar, la obediencia debida o leyes especiales como la 975/2005.

\footnotetext{
${ }^{68}$ Este hecho también lo resalta GONZÁLEZ ZAPATA, J., "Verdad, justicia, paz...", p. 58.

${ }^{69}$ GONZÁlez ZaPATA, J., "Verdad, justicia, paz...”, p. 45.

70 Como lo manifestaron en su momento, entre otros, la ACNUDHC, junio 27 de 2005, p. 2 y la CCJ, "Sin paz y sin justicia", p. 2. De hecho ya se informa del surgimiento de "nuevos" grupos paramilitares, en http://www.elespectador.com, "El vuelo de las águilas negras", 27 de enero de 2007; http://www.eltiempo.com, "Grupos criminales ligados a narcotráfico y paramilitarismo tienen copada media Colombia de nuevo", julio 16 de 2007.
} 
Sotomayor - Criminalidad organizada y criminalidad económica...

\section{A manera de conclusión: los desafíos del derecho en Colombia}

El caso colombiano parece pues una buena prueba de la inconveniencia de asumir "cruzadas" de lucha contra la delincuencia con carácter general, como si pudiera hablarse del mismo fenómeno en todas partes. Como parece que resulta claro de la situación colombiana, aunque las normas e instrumentos de lucha contra la denominada criminalidad organizada sean las mismas, eso no significa la protección de intereses comunes a los diferentes países. Bien se sabe que la mundialización económica no ha sido un proceso al cual acceden todos los países en condiciones de igualdad, y que más bien su consecuencia más notoria está constituida por la concentración de poder en torno a tres polos (Europa, Estados Unidos y Japón). ${ }^{71}$ Luego, como bien explica Terradillos, "un proceso de criminalización que es ejercicio de poder, desigualmente distribuido en los diversos mercados, no puede responder a pautas únicas, ni puede aceptarse como 'natural', sino como fruto de una decisión artificial en que se manifiesta la desigual distribución del poder de definición". ${ }^{72}$

En países como Colombia lo anterior se torna especialmente complejo, por cuanto se trata de un país que, como ha dicho Aponte, vive de manera simultánea en varios siglos de historia: por un lado, le toca enfrentar los dilemas del presente y enfrentar los retos que plantea el desarrollo tecnológico y la globalización económica. Pero, al mismo tiempo, le corresponde resolver los problemas propios de construcción del Estado, por lo tanto más cercanos a los vividos en Europa durante los siglos XVI y XVII. ${ }^{73}$ El desafío está en que le toca abordar la construcción del Estado en un contexto muy distinto al que permitió la construcción de los Estados nacionales en la Europa de los siglos XVI y siguientes: "La cultura de los derechos humanos, tanto a nivel nacional como internacional, así como las demandas de los movimientos sociales y democráticos, impiden -afortunadamente- que la construcción del Estado nacional en Colombia se haga desconociendo los principios del Estado de derecho, bloqueando la participación democrática u olvidando la justicia social. Colombia debe alcanzar un orden público interno en un marco ideológico, normativo y social que hace que las fórmulas absolutistas sean hoy insostenibles, ilegítimas, e incluso contraproducentes en términos puramente pacificadores". ${ }^{74}$

He aquí, pues, la paradoja del derecho y muy particularmente del derecho penal en Colombia: es un arma de guerra -y en tal sentido es un derecho ilegítimoque, como todas, se utiliza para aniquilar o en todo caso vencer al adversario;

\footnotetext{
71 Cfr. Santos, B. DE S., La globalización del Derecho..., p. 40.

72 Terradillos, J., "El derecho penal de la globalización...”, p. 204.

73 ApOnTE, A. D., "Derecho penal de enemigo vs. derecho penal del ciudadano. El derecho penal de emergencia en Colombia: entre la paz y la guerra", en DE GIORGI, R. (a curi di), Il Diritto e la differenza. Scritti in onore di Alessandro Baratta, 2003, p. 257; y PÉREZ TORO, W. F., "Guerra y delito en Colombia", en EP, 2000 (16), p. 14.

${ }^{74}$ Rodríguez, C., Uprimny, R. y García Villegas, M., "Entre el protagonismo y la rutina...”, p. 50; en términos semejantes, APONTE, A., Guerra y derecho penal de enemigo..., pp. 640-649.
} 
pero, también, al mismo tiempo, es una herramienta necesaria en la construcción de un proyecto de ciudadanía, en cuanto mecanismo de protección de los derechos del individuo. Y precisamente esta ambivalencia es la que lo convierte en una herramienta demasiado peligrosa, por los riesgos ciertos y latentes de manipulación política, pues en un contexto de guerra o confrontación interna se tiende a presentar como derecho legítimo a su mera utilización como instrumento bélico.

Por lo anterior, no son trasladables de manera automática las normas ni modelos de intervención surgidos en realidades tan diferentes como la de los países desarrollados. Entre otras razones por cuanto a diferencia del debate europeo, en Colombia no se puede partir del Estado de Derecho (y por ende del derecho penal) y la democracia como datos consolidados, pues éstos más que una realidad son proyectos en construcción. Es posible que en los países centrales el modelo penal de excepción o emergencia que se propone en la lucha contra la criminalidad organizada no suponga un riesgo mayor para el Estado de Derecho, cuya existencia y funcionamiento suele mantenerse al margen de este tipo de discusiones y por lo general constituye su marco. ${ }^{75}$ En la compleja realidad colombiana no sucede de la misma manera por cuanto es el Estado de Derecho mismo el que está por construir, y por ello con demasiada frecuencia las propuestas de excepción a los derechos y garantías fundamentales esconden pretensiones de institucionalización autoritaria.

\footnotetext{
${ }^{75}$ No obstante el deterioro de la cultura de las garantías y del Estado de Derecho apreciable en el último tiempo y que ya ha empezado a aparecer en el propio discurso penal, como ya alertan algunos: ARNOLD, J., "La superación del pasado de la RDA ante las barreras del derecho penal del Estado de Derecho", en INSTITUTO DE CIENCIAS CRIMINALES DE FrANKFURT (ed.), La insostenible situación del Derecho penal, edición española a cargo del Área de Derecho penal de la Universidad Pompeu Fabra, Granada, Comares, 2000, pp. 310-312; ZAFFARONI, E. R., "Globalización y crimen organizado", cit., pp. 11-15; SOTOMAYOR ACOSTA, J. O., "¿El derecho penal garantista en retirada?”, en $R P, 2008$ (21), pp. 148-154.
} 
Sotomayor - Criminalidad organizada y criminalidad económica...

\section{BIBLIOGRAFÍA}

* Albrecht, Hans-Jörg: Criminalidad transnacional, comercio de narcóticos y lavado de dinero, Universidad Externado de Colombia, Bogotá, 2001.

* Albrecht, Peter: "El derecho penal en la intervención de la política populista", en Instituto DE Ciencias CRiminales DE FrankFurT (ed.), La insostenible situación del Derecho penal, edición española a cargo del Área de Derecho penal de la Universidad Pompeu Fabra, Comares, Granada, 2000.

* ANArte Borrallo, Enrique: “Conjeturas sobre la criminalidad organizada”, en Ferré Olivé, J. C. y Anarte Borrallo, E. (Eds.), Delincuencia organizada. Aspectos penales, procesales y criminológicos, Universidad de Huelva, Huelva, 1999.

* APONTE, Alejandro: Guerra y derecho penal de enemigo. Reflexión crítica sobre el eficientismo penal de enemigo, Ibáñez, Bogotá, 2006.

"Derecho penal de enemigo vs. derecho penal del ciudadano. El derecho penal de emergencia en Colombia: entre la paz y la guerra", en DE GIORGI, R. (a curi di), Il Diritto e la differenza. Scritti in onore di Alessandro Baratta, 2003.

* Arias Holguín, Diana: A propósito de la discusión sobre el derecho penal "moderno" y la sociedad del riesgo, Cuaderno de Investigación, No. 42, Medellín, Universidad EAFIT, 2006.

“Lavado de activos y 'modernización' del derecho penal: el caso colombiano", en NFP, 2007 (70).

* ARNOLD, Jörg: "La superación del pasado de la RDA ante las barreras del derecho penal del Estado de Derecho", en INSTITUTO DE CiENCIAS CRIMINALES DE FrANKFuRT (ed.), La insostenible situación del Derecho penal, edición española a cargo del Área de Derecho penal de la Universidad Pompeu Fabra, Comares, Granada, 2000.

* BECK, Ulrich: La sociedad del riesgo. Hacia una nueva modernidad, Barcelona, Paidós, 2006.

- BotTKE, Wilfried: "Mercado, criminalidad organizada y blanqueo de dinero en Alemania", en RP, 1998 (2).

* Bustos Ramírez, Juan: "Criminología crítica y derecho penal latinoamericano", en Obras Completas, Tomo II: Control social y otros estudios, ARA Editores, Lima, 2004.

"Estructura jurídica y Estado en América Latina", en RuSCHE, G. y Kirchheimer, O., Pena y estructura social, Temis, Bogotá, 1984.

* Calle Calderón, A. L.: “Acerca de la reforma procesal penal. Una primera aproximación”, en NFP, 2005 (67).

* Capella Hernández, Juan: "Estado y derecho ante la mundialización: aspectos y problemáticas generales”, en CAPELLA HERNÁNDEZ, J. R. (Coordinador), Transformaciones del derecho en la mundialización, Consejo General del Poder Judicial, Madrid, 1999.

* Carranza, Elías y otros: El preso sin condena en América Latina y el Caribe, ILANUD, San José, 1998.

* Cervini, Raúl: "Los filtros sistémicos del crimen organizado en materia económica y financiera", en YACOBUCCI, G. (Coordinador), El crimen organizado. Desafios y perspectivas en el marco de la globalización, Abaco de Rodolfo Depalma, Buenos Aires, 2005.

* Choclán Montalvo, José: "Criminalidad organizada. Concepto. La asociación ilícita. Problemas de autoría y participación”, en GRANADOS PÉREZ, C. (Director), La criminalidad organizada. Aspectos sustantivos, procesales y orgánicos, Consejo General del Poder Judicial, Madrid, 2001.

* Del Olmo, Rosa: América Latina y su criminología, Siglo XXI, México, 1984.

* De la Cuesta ArZAmendi, José: "El derecho penal ante la criminalidad organizada: nuevos retos y límites”, en GUTIÉRREZ-ALviz CONRADO, F. y VALCÁRCE LÓPEZ, M. (Directores), La cooperación internacional frente a la criminalidad organizada, Universidad de Sevilla, Sevilla, 2001. 
REJ - Revista de Estudios de la Justicia - No 12 - Año 2010

* DíEz Ripollés, José: "De la sociedad del riesgo a la seguridad ciudadana", Revista electrónica de ciencia penal y criminología, 7, 2005. La politica criminal en la encrucijada, BdeF, Montevideo-Buenos Aires, 2007.

* Donini, Massimo: "Escenarios del Derecho penal en Europa a principios del siglo XXI”, en Mir Puig, S. y Corcoy Bidasolo, M. (Directores) - Gómez Martín, V. (Coordinador), La politica criminal en Europa, Atelier, Barcelona, 2004.

Il volto attuale dellillecito penale. La democrażia penale tra differenziazione e sussidiarietà, Giuffrè, Milano, 2004.

"El derecho penal frente al 'enemigo", en CANCIO MELIÁ - GÓMEZ-Jara DíEZ (coordinadores), Derecho penal de enemigo. El discurso penal de la exclusión, vol. 1, EdisoferBdeF, Madrid- Buenos Aires-Montevideo, 2006.

"Non puniblità e idea negoziale", en DONINI, M., Alla ricerca de un disegno. Scritti sulle riforme penali in Italia, CEDAM, Padova, 2003.

* Faraldo Cabana, Patricia: "Medidas premiales durante la ejecución de condenas por terrorismo y delincuencia organizada: consolidación de un subsistema penitenciario de excepción", en CANCiO MELIÁ - GÓMEZ-JARA DíEZ (Coordinadores), Derecho penal de enemigo. El discurso penal de la exclusión, vol. 1, Edisofer-BdeF, Madrid-Buenos AiresMontevideo, 2006.

* Ferrajoli, Luigi: "Crisi della legalitá e diritto penale minimo", en Curi, U. y Palombarini, G. (a cura di), Diritto penale minimo, Donzelli, Roma, 2002.

* FiAndaCA, Giovanna: "Criminalità organizzata e controllo penale", en BASSIOUNI, M. C., Latagliata, A., R. y STiLe, A. M., (a cura di), Studi in onore di Giuliano Vassalli. Evoluzione e riforma del diritto e della procedura penale (1945-1990), Volumen II, Giuffrè, Milano, 1991.

* Foffani, Luigi: "Criminalidad organizada y criminalidad económica”, en RP, 2001 (7).

* Gaitán Daza, Fernando: "Multicausalidad, impunidad y violencia: una visión alternativa”, en REI, 2001 (5).

* García MÉndez, Emilio: Autoritarismo y control social (Argentina-Uruguay-Chile), Hammurabi, Buenos Aires, 1987.

* Garrido, Vicente, Stangeland, Per y Redondo, Santiago: Principios de criminología, Tirant lo blanch, Valencia, 2006.

* Garzón VAldÉs, Ernesto: "Acerca de las funciones del derecho en América Latina". Cuadernos de la Facultad de Derecho, Universidad de Palma de Mallorca, 31982.

* Gómez de Liaño Fonseca-Herrero, Marta: Criminalidad organizada y medios extraordinarios de investigación, Colex, Madrid, 2004.

* GonZÁlez Zapata, Julio: "Verdad, justicia, paz y reparación en la mitología penal. A propósito de la ley 975 de 2005”, en EP, 2005 (27).

* Gordon Atehortúa, Liliana y Kury, H.: "Victimización como hecho cotidiano. Un estudio victimológico en Colombia”, en RDPC, 2006 (18).

* Gracia Martín, Luis: Prolegómenos para la lucha por la modernización y expansión del Derecho penal y para la crítica del discurso de resistencia, Tirant lo Blanch, Valencia, 2003.

* Grosso García, Manuel: La reforma del sistema penal colombiano, Gustavo Ibáñez, Bogotá, 1999.

* Guerrero Peralta, Oscar: "La policía en el Estado de Derecho latinoamericano: el caso Colombia”, en Ambos, K., Gómez Colomer, J. L. y Vogler, R. (editores), La policía en los estados de derecho latinoamericanos: un proyecto internacional de investigación, Gustavo Ibáñez, Bogotá, 2003.

* Hassemer, Winfried: "Viejo y nuevo derecho penal", AAVV, La responsabilidad por el producto en derecho penal, Tirant lo Blanch, Valencia, 1995.

"Rasgos y crisis del derecho penal moderno", en Anuario de Derecho Penal y Ciencias Penales, Madrid, 1992. 
Sotomayor - Criminalidad organizada y criminalidad económica...

* Hernández, Tosca: La ideologización del delito y de la pena, Universidad Central de Venezuela, Caracas, 1977.

* Insolera, Gaetano: "Nociones de criminalidad organizada: concurso de personas y delitos asociativos", en VIRGOLINI - SLOKAR (Coordinadores), Nada personal... Ensayos sobre crimen organizado y sistema de justicia, Depalma, Buenos Aires, 2001.

* Laurenzo Copello, Patricia: Dolo y conocimiento, Tirant lo Blanch, Valencia, 1999.

* López Medina, Diego: Teoría impura del derecho. La transformación de la cultura jurídica latinoamericana, Legis-Universidad de Los Andes, Universidad Nacional, Bogotá, 2004.

* Medina Ariza, Juan: "Una introducción al estudio criminológico del crimen organizado", en Ferré Olivé, J. C. y AnArte Borrallo, E. (Eds.), Delincuencia organizada. Aspectos penales, procesales y criminológicos, Universidad de Huelva, Huelva, 1999.

* Mendoza Buergo, Blanca: El Derecho penal en la sociedad del riesgo, Civitas, Madrid, 2001.

* Mercado, Pedro: "El proceso de globalización, el Estado y el Derecho", en Portilla Contreras, G., Mutaciones del Leviatán. Legitimación de los nuevos modelos penales, Universidad Internacional de Andalucía - Akal, Madrid, 2005.

* Moccia, Sergio: La perenne emergenza. Tendenze autoritarie nel sistema penale, $2^{\mathrm{a}}$ ed., Edizioni Scientifiche Italiane, Napoli, 1997.

"De la tutela de bienes a la tutela de funciones: entre ilusiones postmodernas y reflujos iliberales", en SILVA SÁNCHEZ, J. M. (editor), Política criminal y nuevo Derecho penal. Libro homenaje a C. Roxin, J. M. Bosch, Barcelona, 1997.

* Musco, Enzo: “Los colaboradores de la justicia entre el 'pentitismo' y la calumnia: problemas y perspectivas", en RP, 1998 (2).

* ORsi, Omar: Sistema penal y crimen organizado. Estrategias de aprehensión y criminalización del conflicto, Del Puerto, Buenos Aires, 2007.

* Paredes Castañón, José: "Sobre el concepto de Derecho penal del riesgo: algunas notas", en DPCRI, 2003.

* Pavarini, Massimo: "Lo sguardo artificiale sul crimine organizzato", en Giostra, G. e INSOLERA, G. (a cura di), Lotta alla criminalità organizzata: gli strumenti normativi, Giuffrè, Milano, 1995

“Lucha contra la criminalidad organizada y 'negociación' de la pena”, en VIRGOLINI - SLOKAR (Coordinadores), Nada personal... Ensayos sobre crimen organizado y sistema de justicia, Depalma, Buenos Aires, 2001.

* Pecaut, Daniel: "Presente, pasado y futuro de la violencia", en AP, 1997 (30).

* Pérez Toro, William: “Guerra y delito en Colombia”, en EP, 2000 (16).

* Restrepo, Elvira y Martínez CuÉllar, Mariana: "Impunidad penal: mitos y realidades", Documento CEDE 2004-4, Bogotá, Universidad de los Andes, 2004 [consultado en http://economia.uniandes.edu.co].

* Restrepo, Elvira, SÁnchez Torres, Fabio y Martínez, Mariana: “iImpunidad o castigo? Análisis e implicaciones de la investigación penal en secuestro, terrorismo y peculado", Bogotá, Documento CEDE 2004-09, Universidad de los Andes, 2004, en http://economia.uniandes.edu.co [consultado el 27/06/2007].

* Rodríguez, César, Uprimny, Rodrigo y García Villegas, Mauricio: "Entre el protagonismo y la rutina: análisis sociojurídico de la justicia en Colombia" en http://www.djs.org.co [consultado 21/06/2007].

* Rubio, Mauricio: "Crimen con misterio. La calidad de la información sobre criminalidad y violencia en Colombia”, Bogotá, CEDE, Universidad de los Andes, 1998 [consultado en: http://economia.uniandes.edu.co].

"Crimen sin sumario. Análisis económico de la justicia penal colombiana", Bogotá, CEDE, Universidad de los Andes, 1998, en http://economia.uniandes.edu.co [consultado el 27/06/2007]. 
REJ - Revista de Estudios de la Justicia - No 12 - Año 2010

* SÁnchez García de PAZ, Isabel: La criminalidad organizada. Aspectos penales, procesales, administrativos y policiales, Dykinson, Madrid, 2005.

- SANTos, Boaventura de Sousa: La globalización del Derecho. Los nuevos caminos de la regulación y la emancipación, Universidad Nacional-ILSA, Bogotá, 1998.

* SChÜnemann, Brend: Consideraciones críticas sobre la situación espiritual de la ciencia jurídico penal alemana, U. Externado de Colombia, Bogotá, 1996.

* Silva SÁnchez, Jesús: La expansión del derecho penal. Aspectos de la política criminal en las sociedades postindustriales, $2^{\mathrm{a}}$ edición, Civitas, Madrid, 2001.

* Sotomayor Acosta, Juan: "Garantismo y derecho penal en Colombia”, en JD, 1999 (35).

"Las recientes reformas penales en Colombia: un ejemplo de irracionalidad legislativa”, en DíEz RipOllÉs, J. L. - GARCíA PÉREZ, O. (Coordinadores), La política legislativa penal iberoamericana, Edisofer-BdeF, Madrid-Montevideo-Buenos Aires, 2008 (en prensa).

Inimputabilidad y sistema penal, Temis, Bogotá, 1996.

“¿El derecho penal garantista en retirada?”, en RP, 2008 (21).

* STELla, Federico: Giustizia e modernità. La protezione dell'innocente e la tutela delle vittime, $3^{\mathrm{a}}$ ed., Giuffrè, Milano, 2003.

* Sûss, Frank: "El trato actual del mandato de determinación", en InSTITUTO DE CIENCIAS CRIminales De FrankfurT (ed.), La insostenible situación del Derecho penal, edición española a cargo del Área de Derecho penal de la Universidad Pompeu Fabra, Comares, Granada, 2000.

* Terradillos, Juan: "El derecho penal de la globalización: luces y sombras", en CAPELla HeRnÁNDEZ, J. R. (Coordinador), Transformaciones del derecho en la mundialización, Madrid, Consejo General del Poder Judicial, 1999.

Peligrosidad social y Estado de Derecho, Akal, Madrid, 1981.

* UprimnY, Rodrigo: "La justicia colombiana en la encrucijada", p. 2, en http://www.djs.org.co [consultado el 21/06/2007].

* Weigend, Van Den: "Los sistemas penales frente al reto del crimen organizado", en RIDP, 1997 (68).

* YACOBUCCI, Guillermo: "Política criminal y delincuencia organizada", en YACOBUCCI, G. (Coordinador), El crimen organizado. Desafíos y perspectivas en el marco de la globalización, Abaco de Rodolfo Depalma, Buenos Aires, 2005.

* ZAFFaroni, Eugenio: El crimen organizado. Una categoría frustrada, Bogotá, Leyer, 1996. "En torno al concepto de "crimen organizado" ", en VIRGOLINI - SLOKAR (Coordinadores), Nada personal... Ensayos sobre crimen organizado y sistema de justicia, Depalma, Buenos Aires, 2001.

"Globalización y crimen organizado", Conferencia de clausura de la Primera Conferencia Mundial de Derecho Penal, organizada por la Asociación Internacional de Derecho Pneal (AIDP), Guadalajara (Mexico), 22 de noviembre de 2007. disponible en www.cienciaspenales.net.

* ZúÑiga RodrígueZ, Laura: "Criminalidad organizada, Unión Europea y sanciones a empresas", consultado http://www.unifr.ch/ddp1/derechopenal/articulos/html/artzuniga.html.

"Criminalidad de empresa, criminalidad organizada y modelos de imputación penal”, en Ferré Olivé, J. C. y AnArte Borrallo, E. (Eds.), Delincuencia organizada Aspectos penales, procesales y criminológicos, Universidad de Huelva, Huelva, 1999.

Bases para un modelo de imputación de responsabilidad penal a las personas jurídicas, $2^{\mathrm{a}}$ edición, Aranzadi, Pamplona, 2003. 
Sotomayor - Criminalidad organizada y criminalidad económica...

\section{ABREVIATURAS}

ACNUR

CNUDHC

AP

ASFADDES

CCJ

CEJ

CEJOSPA

$\mathrm{CIDH}$

CP

CPP

CSJ

DPCRI

EP

GC

HRW

INPEC

JD

NFP

$\mathrm{RC}$

RDPC

REI

RIDP

RP
Alto Comisionado de las Naciones Unidas para los Refugiados.

Alta Comisionada de las Naciones Unidas para los Derechos Humanos en Colombia

Análisis Político

Asociación de Familiares de Detenidos Desaparecidos

Comisión Colombiana de Juristas

Corporación Excelencia en la Justicia

Corporación Excelencia en la Justicia Observatorio del Sistema Penal Acusatorio

Comisión Interamericana de Derechos Humanos

Código penal

Código de procedimiento penal

Corte Suprema de Justicia

Derecho Penal Contemporáneo. Revista Internacional

Estudios Políticos

Gaceta del Congreso

Human Rights Watch

Instituto Nacional Penitenciario y Carcelario

Jueces para la Democracia

Nuevo Foro Penal

Revista Criminalidad

Revista de Derecho Penal y Criminología (Madrid)

Revista de Economía Institucional

Revue Internationale de Droit Pénal

Revista Penal 